This discussion paper is/has been under review for the journal Atmospheric Chemistry and Physics (ACP). Please refer to the corresponding final paper in ACP if available.

\title{
High resolution assimilation of IASI ozone data with a global CTM
}

\section{B. Pajot $^{1}$, S. Massart ${ }^{1}$, D. Cariolle ${ }^{1,6}$, A. Piacentini ${ }^{1}$, O. Pannekoucke ${ }^{2}$, W. A. Lahoz ${ }^{3}$, C. Clerbaux ${ }^{4,5}$, P. F. Coheur ${ }^{5}$, and D. Hurtmans ${ }^{5}$}

${ }^{1}$ CERFACS/SUC CNRS-URA1875, AE team, 42 avenue Gaspard Coriolis, 31057 Toulouse, France

${ }^{2}$ CNRM/GAME, Météo-France/CNRS-URA1357, 42 avenue Gaspard Coriolis, 31057

Toulouse, France

${ }^{3}$ NILU, P.O. Box 100, 2027 Kjeller, Norway

${ }^{4}$ UPMC Univ. Paris 6; Université Versailles St.-Quentin; CNRS/INSU, LATMOS-IPSL, Paris, France

${ }^{5}$ Spectroscopie de l'Atmosphère, Chimie Quantique et Photophysique, Université Libre de Bruxelles, Brussels, Belgium

${ }^{6}$ Météo-France, 42 avenue Gaspard Coriolis, 31057 Toulouse, France

Received: 5 October 2011 - Accepted: 18 October 2011 - Published: 31 October 2011

Correspondence to: B. Pajot (pajot@cerfacs.fr)

Published by Copernicus Publications on behalf of the European Geosciences Union.
High resolution assimilation

B. Pajot et al.

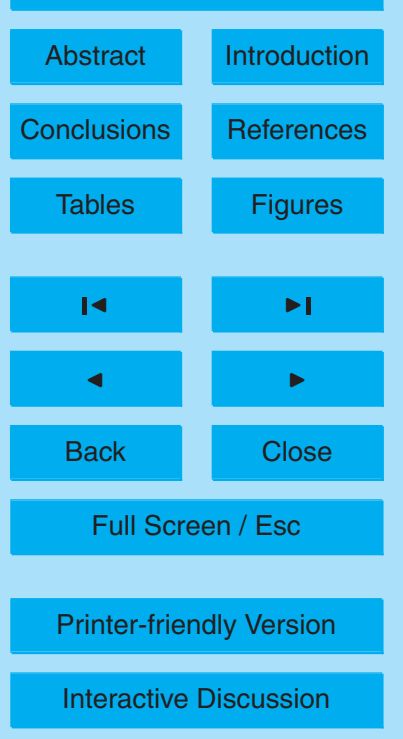




\section{Abstract}

The pixel size of the Infrared Atmospheric Sounding Interferometer (IASI) remote sensor is much smaller than the horizontal grid size of current Chemical Transport Models (CTMs). In order to assimilate the maximum of information from the IASI retrievals, we

5 have increased the horizontal resolution of our model MOCAGE to be consistent with the IASI pixel size. Experiments are carried out with the Valentina data assimilation system using the standard and the high resolution versions of the model. Two resolutions of the horizontal Gaussian grid have been used for the model: with a T42 and a T170 triangular truncations. Our study is based on the combination of data from the 10 IASI instrument and from the Microwave Limb Sounder (MLS), since this latter dataset allows the information to be spread through the whole atmospheric columns at a low computational cost. Two datasets of ozone super-observations have been constructed by averaging the IASI data on the two model grids.

Direct model simulations without data assimilation first show that the increase of 15 the horizontal resolution modifies the ozone smallest scale structures as well as the ozone meridional distribution. This modification results from a better representation of the vertical velocity with the T170 configuration. When the ozone assimilation is performed there is less influence of the horizontal resolution of the model. Nevertheless, in a general way, comparisons with independent data show large reductions of the ozone standard deviations when the resolution is increased. When the ozone assimilation is performed with the high resolution dataset, the high resolution model does not improve the ozone analysis compared to the one obtained with the same model resolution but with the low resolution IASI dataset. This result is due to the difficulty to combine IASI data and MLS data. For assimilating IASI data at high resolution the horizontal correlation length-scale has to be decreased to catch the small scale structures present in the dataset. By doing so the influence of the coarser resolution MLS data is decreased and part of the information brought on the vertical shape of the ozone profile is lost. It is concluded that it is essential to add information on the vertical distribution of ozone

\section{High resolution assimilation}

B. Pajot et al.

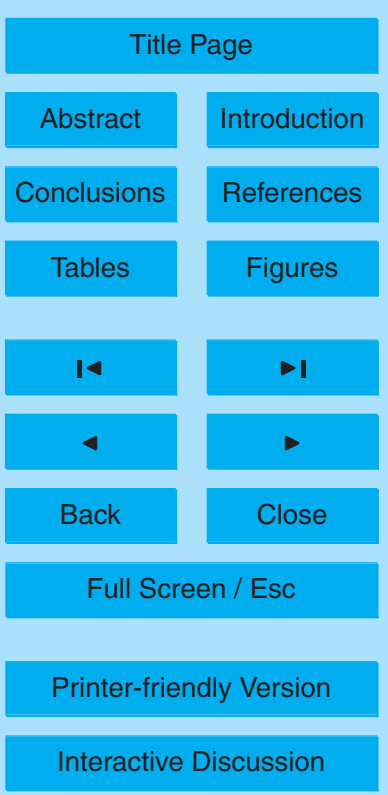


column when the IASI data is assimilated at a resolution close to the pixel size. Using IASI averaging kernels would likely improve the simulations, but the computational cost would be much higher. Alternatively, better results might be obtained by a careful tuning of the horizontal correlation length-scale.

\section{Introduction}

Present day data assimilation systems for atmospheric chemistry are robust, efficient and are used for either scientific investigations or operational monitoring of the chemical composition of the atmosphere (Lahoz et al., 2007). Chemical data assimilation experiments for climate studies are usually built on top of General Circulation Models 10 (GCMs) that often use simplified chemistry schemes. But for data assimilation experiments that aim to study the distribution of atmospheric species whose chemistry and transport time scales are of the same order of magnitude, Chemical Transport Models (CTMs) are widely used. For instance, operational chemical forecasts based on an analysis from an operational data assimilation suite that use CTMs are developed at 15 the Belgian Institute for Space Aeronomy (BIRA), the Royal Netherlands Meteorological Institute (KNMI) and the National Aeronautics and Space Administration (NASA).

The global CTMs used for data assimilation by these centres have rather coarse horizontal resolutions, with grid size generally higher than $2^{\circ}$. As an example, the Belgian Assimilation System for Chemical ObsErvations (BASCOE) from BIRA has 20 a horizontal resolution of $3.75^{\circ} \times 5^{\circ}$ (Errera et al., 2008) or $2.5^{\circ} \times 3.75^{\circ}$ (Lahoz et al., 2011). The TM5 model from KNMI has a global horizontal resolution of $4^{\circ} \times 6^{\circ}$ or $2^{\circ} \times 3^{\circ}$ (Huijnen et al., 2010). Notably the 30-year reanalysis of total ozone made at KNMI is on a grid of $2^{\circ} \times 3^{\circ}$ (van der A et al., 2010). And the Global Modeling Initiative (GMI) model of NASA has been used for stratospheric modelling with a horizontal resolution
ACPD

High resolution assimilation

B. Pajot et al.

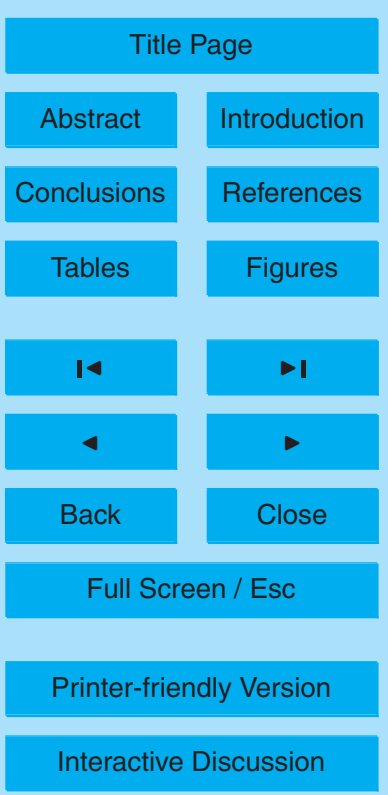


These usual model resolutions are much coarser than the pixel size of new generation on-board instruments such as: a $13 \times 24 \mathrm{~km}^{2}$ footprint (that corresponds to $0.12^{\circ} \times 0.22^{\circ}$ at the equator) for the Ozone Monitoring Instrument (OMI, Levelt et al., 2006) or a $12 \mathrm{~km}$ footprint (that corresponds to $0.11^{\circ}$ at the equator) for the Infrared At5 mospheric Sounding Interferometer (IASI, Clerbaux et al., 2009). One method widely applied to assimilate such data consists in an appropriate averaging of all the data measured within a model cell for a given time frame. The process is known as the creation of super-observations (Lorenc, 1981).

The average resulting from the creation of super-observations generates a loss of 10 information. This may for example smooth the gradients or prevent the representation of local phenomena. Increasing the model resolution to the observational resolution is not always possible due to computational limitations in terms of time and memory. However a model resolution increase is required to use super-observations close to the datasets resolution and thus to better take into account the small scale information 15 available in the dataset. The focus of this paper is to measure the expected improvements brought by the use of a global chemical data assimilation performed at a higher resolution than the usual ones. By higher resolution we mean both a higher resolution of the CTM horizontal resolution and consistent high-resolution super-observations that have to be assimilated.

20

The first dataset used for our assimilation is the ozone profiles from the Microwave Limb Sounder (MLS, Froidevaux et al., 2008; Livesey et al., 2008). The MLS data allows the constraint of the vertical distribution of the ozone in the stratosphere and the upper troposphere. But the horizontal resolution of MLS is about $1.5^{\circ}$ that is comparable to the CTMs usual low resolution. The second dataset used, the IASI total ozone columns, has a much better horizontal resolution but brings little information on the vertical ozone distribution. The two datasets are complementary.

To evaluate the influence of the model horizontal resolution, the assimilation experiments have been carried out with the MOdèle de Chimie Atmosphérique à Grande Échelle (MOCAGE) developed at Centre National de Recherches Météorologiques
ACPD

11, 29357-29406, 2011

High resolution assimilation

B. Pajot et al.

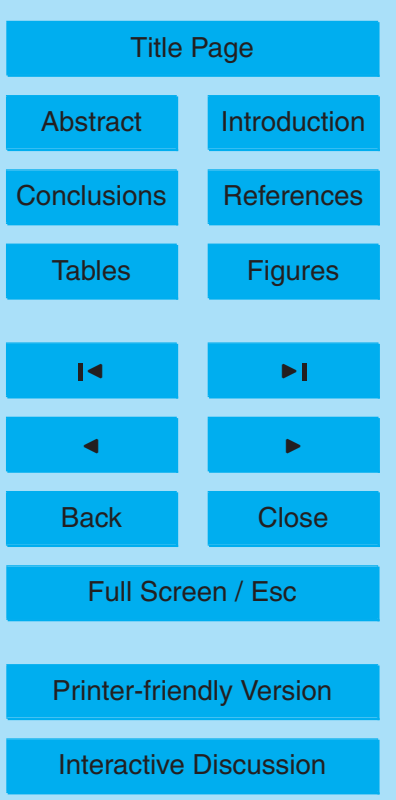


(CNRM) of Météo-France. MOCAGE has been used at two horizontal resolutions: a so-called T42 low resolution (corresponding approximately to $2.8^{\circ} \times 2.8^{\circ}$ with 64 by 128 Gaussian grid cells) and a high resolution one, so-called T170 (corresponding approximately to $0.7^{\circ} \times 0.7^{\circ}$ with 256 by 512 Gaussian grid cells). To be consistent with 5 these model resolutions, two datasets of IASI ozone total columns super-observations, combined with MLS ozone profiles, are built for the assimilation: the IASI dataset is averaged on the T42 (T170) low (high) resolution grid, what we simply call T42 (T170) IASI \& MLS dataset.

The assimilation experiments are performed with the Valentina data assimilation sys10 tem developed at the Centre Européen de Recherche et Formation Avancée en Calcul Scientifique (CERFACS). We investigate the period of the month of September 2008. Over the South Pole (SP), it is the end of the polar night and the sunlight is progressing towards the high latitudes. This period sees the formation of the Antarctic ozone hole with large ozone gradients at its boundary and filamentary structures extracted at the 15 edge of the associated polar vortex. A situation that is particularly interesting to study the quality of a global ozone analyses.

The present paper is structured as follows. The next section details the characteristics of the ozone data used in this study. Section 3 describes the methodology used to produce the analyses. In Sect. 4 the model simulations are discussed with emphasis on the impact of the horizontal resolution. The model simulations without assimilation are first analysed, followed by comparisons of the analyses to independent datasets: in situ and satellite measurements, and the ERA-interim ozone analyses produced by the European Centre for Medium-Range Weather Forecasts (ECMWF). Finally in Sect. 5 we assess the ability of our model suite to assimilate the high resolution information from the IASI observations.

High resolution assimilation

B. Pajot et al.

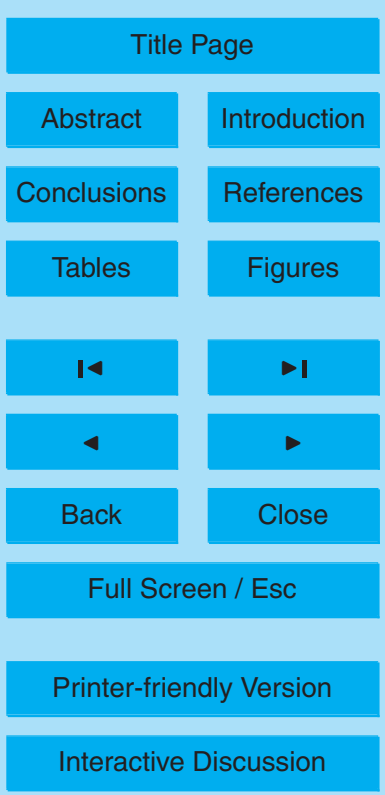

Interactive Discussion 


\section{Ozone data}

The assimilated ozone data from MetOp-A/IASI and the profiles from Aura/MLS are described below in Sect. 2.1. The independent sources of information used for validation (Sect. 2.2) come from the ozone reanalyses of the ECMWF, the total ozone columns 5 of the $\mathrm{OMI}$ instrument and the ozone profiles of the ozonesondes.

\subsection{Ozone observations for the assimilation}

\subsubsection{The IASI total ozone columns}

The polar orbiting MetOp-A satellite carrying the IASI instrument on board was launched in October 2006. IASI measures the spectrum of infrared radiation (IR) emit-

10 ted by the Earth-atmosphere system, from a low altitude sun-synchronous polar orbit, over a swath width of $\sim 2200 \mathrm{~km}$, every $50 \mathrm{~km}$ at nadir (with 4 footprints of $12 \mathrm{~km}$ in diameter). The MetOp-A satellite takes about $100 \mathrm{~min}$ to complete one orbit, and therefore a complete mapping of the Earth is obtained in about $12 \mathrm{~h}$. IASI provides a good compromise between the meteorology requirements (high spatial coverage) and the 15 atmospheric chemistry needs (accuracy for trace gases). In particular, essential chemical components like methane, carbon monoxide, ozone and other trace gases that play a key role in the atmospheric chemistry can be retrieved from IASI measurements (Clerbaux et al., 2009; Clarisse et al., 2011).

A fast retrieval approach named FORLI (Fast Operational/Optimal Retrieval on Layers for IASI) based on the optimal estimation theory has been used to provide the ozone global distribution profiles in near real time (Dufour et al., 2011; Scannell et al., 2011). In this study we use the total ozone column products for cloud-free observations. For simplicity, the IASI ozone retrievals from FORLI are referred to as IASI data. These retrievals have a lower error and a better horizontal coverage than the ones 25 assimilated in the previous study of Massart et al. (2009), in particular over the polar regions.

High resolution assimilation

B. Pajot et al.

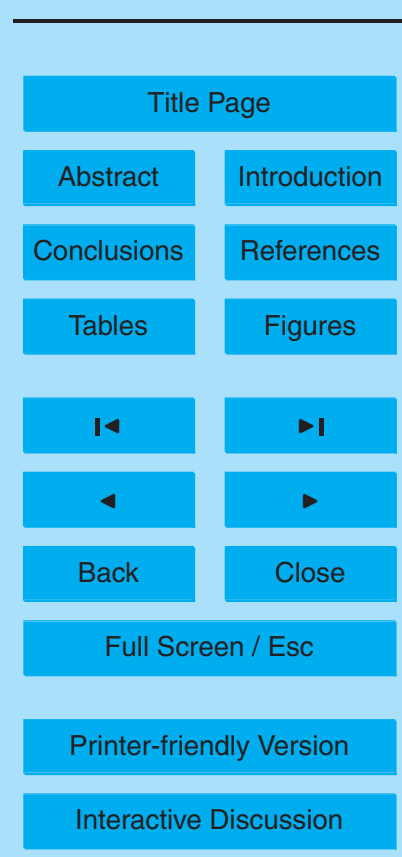

Interactive Discussion 
The averaging kernels (AKs) associated with the IASI retrievals are a product of FORLI along with the column contents. Unfortunately, due to computational limitations, this vertical distribution information had to be discarded in our system when working with a high resolution of the MOCAGE model. To be consistent in our assessment, we 5 choose to neglect it also with a low resolution of the MOCAGE model. Alternatively, a constraint on the vertical ozone distribution over the stratosphere and the upper troposphere is ensured by the joint assimilation of Aura/MLS observed profiles.

For the period under study, there are 5 days (from 16 to 20 September) without IASI measurements due to MetOp-A calibration. Otherwise, an average of about 300000 10 retrievals of total ozone column are produced per day. To assimilate these data into the T42 model and the T170 one, we build super-observations. They are obtained by the computation of the simple mean of all the observations made within a minute inside the same model cell. When the targeted grid is the T42 (T170) one, the obtained dataset is hereafter referred to as the T42 (T170) IASI data. This procedure reduces the daily 15 number of observations as shown in Table 1.

\subsubsection{The Aura/MLS ozone profiles}

The MLS instrument has been flying onboard the Aura satellite in a sun-synchronous polar orbit since August 2004. We choose to assimilate the v2.2 version of MLS ozone product, notably because a detailed validation of this product and comparisons with 20 other datasets already exist (Froidevaux et al., 2008; Livesey et al., 2008). The latter works show in particular that in the middle stratosphere the MLS ozone data have small biases, with a random error of the order of $5 \%$. MLS also measures constituents in the Upper Troposphere-Lower Stratosphere (UTLS) where retrievals are made at 4 levels, namely $215,147,100$ and $68 \mathrm{hPa}$. Nevertheless, the error is higher in this region with 25 values in the range $5 \%$ to $100 \%$ below $100 \mathrm{hPa}$, from $2 \%$ to $30 \%$ at $100 \mathrm{hPa}$, while it is below $10 \%$ at lower pressure levels.

In previous studies we have assimilated the MLS data with a CTM at a $2^{\circ} \times 2^{\circ}$ resolution. Since this resolution is lower than the $1.5^{\circ}$ distance of two successive MLS

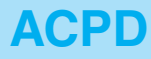

11, 29357-29406, 2011

\section{High resolution assimilation}

B. Pajot et al.

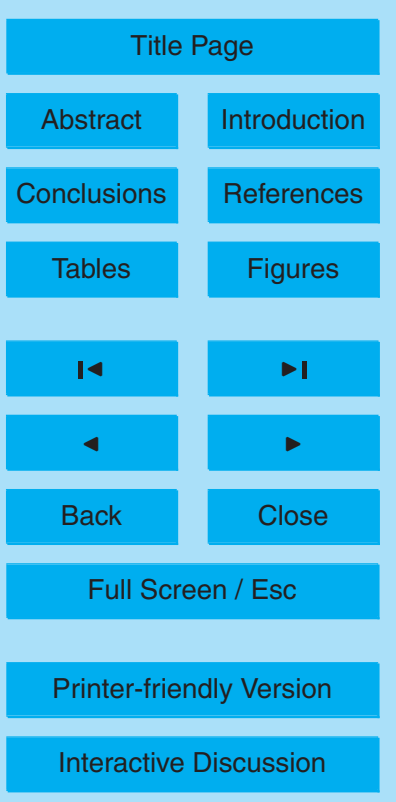

Interactive Discussion 
scans, we had to construct super-observations. The assimilation of the resulting superobservations set for the period studied in this paper was well characterized in Massart et al. (2011), so they are also used in the present study. For the period in consideration, it gives about 2000 measurements at 16 pressure levels per day with a distribution 5 by bands of latitude given in Table 1. During the period under study, there is no day without MLS measurements. A complete description of the Aura/MLS profiles and their usual treatments in the Valentina assimilation system can be found in Massart et al. (2011).

\subsection{Ozone data for model validation}

\subsubsection{ERA-Interim reanalyses}

ERA-Interim is a reanalysis of the global atmosphere covering the data-rich period from 1989 to the present, and continuing to present (Berrisford et al., 2009). The ERAInterim project was initiated in 2006 to provide a bridge between ECMWF's previous reanalysis, ERA-40, and the next-generation extended reanalysis that has just begun at ECMWF. The ERA-Interim reanalysis was made to improve the quality of the stratospheric circulation compared to the ERA analysis. This is an important point for the present study. These data are known to be of good quality: they have been favourably compared with in situ measurements and with satellite data (Dragani, 2011).

The horizontal resolution of the reanalysis products of ERA-Interim is a N128 reduced Gaussian grid (512 longitude points and 256 latitude points), that corresponds to a spacing of about $0.7^{\circ}$ (about $77 \mathrm{~km}$ at the equator). The atmosphere is divided into 60 vertical layers from the surface up to $0.1 \mathrm{hPa}$. The vertical resolution is finer in the planetary boundary layer and coarser in the stratosphere and mesosphere.

The ERA-Interim reanalysis system uses a 4-dimensional variational (4D-Var) anal25 ysis and a variational bias correction for satellite data. We have used the analyses produced at 00:00 and 12:00 UTC. For the period under study, the ozone data assimilated to produce the ERA-Interim data comes from the instruments MLS, OMI, SCanning

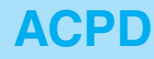

11, 29357-29406, 2011

High resolution assimilation

B. Pajot et al.

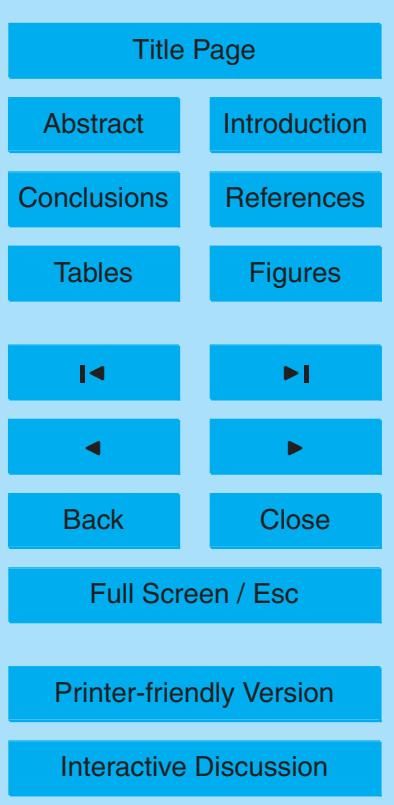


Imaging Absorption spectroMeter for Atmospheric CartograpHY (SCIAMACHY) and Solar Backscatter Ultraviolet (SBUV) with a total daily count of approximately $10^{5} \mathrm{ob}-$ servations (Dee et al., 2011). As the MLS data are used to produce the ERA-Interim reanalysis and our ozone analysis, both datasets are not entirely independent and we expect in particular good consistency in their vertical distributions.

Since we perform assimilation experiments with the high T170 resolution of the model, the ERA-Interim reanalyses are interpolated from the N128 reduced Gaussian grid to the T170 Gaussian grid to make diagnostics. The differences between the ozone concentration from our experiments and the one from the ERA-Interim reanaly10 ses are computed every $12 \mathrm{~h}$ on the T170 grid on model levels and for the total ozone columns. From them monthly statistics are derived.

\subsubsection{OMI-DOAS total ozone columns}

On board the Aura satellite, OMI is a nadir viewing imaging spectrograph that measures the solar radiation backscattered by the Earth's atmosphere and surface (Levelt 15 et al., 2006). OMl combines the advantages of European Space Agency (ESA) instruments Global Ozone Monitoring Experiment (GOME) and SCIAMACHY with the characteristics of the NASA's Total Ozone Mapping Spectrometer (TOMS) instrument. It measures the complete spectrum in the ultraviolet (UV) and visible wavelength range with a spatial resolution higher than its presursors and a daily global coverage. It is 20 thus of particular interest to compare analyses made with the IASI IR data with these UV ones, since they are derived from different spectral bands of absorption.

In this study, we use the OMI total ozone columns data (available from http://www. temis.nl) produced with the KNMI DOAS method (Veefkind et al., 2006). The OMI total ozone columns have showed a globally averaged agreement better than $2 \%$ with the 25 ground-based observations (Balis et al., 2007). The data show no significant dependence on latitude except for the high latitudes of the Southern Hemisphere $(\mathrm{SH})$ where it systematically overestimates the total ozone value by $3-5 \%$. In a manner consistent with the assimilated datasets, we average the measurements on each cell of the 29365

High resolution assimilation

B. Pajot et al.

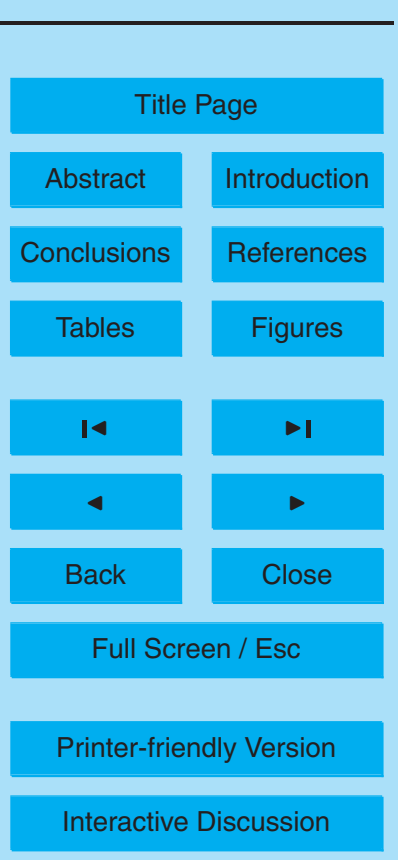


T170 grid. The daily number of resulting observations is given in Table 1 per bands of latitude. The resulting dataset is hereafter referred to as OMI data.

For each OMI measurement, the co-located (in space and time) model total column is computed using its nearest neighbours for the spatial interpolation and a linear time

5 interpolation between the $12 \mathrm{~h}$ step analyses. The differences between OMI data and the assimilation products are normalized by the observation measurement. We add a rejection threshold of the observed total column when the difference is higher than $40 \%$. With this threshold, very few observations are rejected and the results remain consistent for the whole month, except over the Northern Polar Region (NPR) for the 10 last days of September.

\subsubsection{Ozonesondes}

Ozone soundings were obtained from the World Ozone and Ultraviolet Radiation Data Centre (WOUDC, http://www.woudc.org/). We have used data from 11 locations for a total number of 47 observations mainly located in the $\mathrm{SH}$. All of these stations are equipped with Electrochemical Concentration Cell (ECC) sondes. According to laboratory comparisons (Smit and Kley, 1998), the random variability of the overall data is estimated at about $10-15 \%$ in the UTLS and near $5 \%$ in the middle stratosphere where ozone concentrations are at their maximum.

To compare ozonesondes measurements with our results, all the observed profiles 20 have been interpolated to a common vertical pressure grid. Then, for each interpolated observed profile, the co-located model profile is computed using its nearest neighbours for the spatial interpolation and the assimilation is output at 12:00 UTC. Following Geer et al. (2006), the difference in the vertical profiles is normalized by a combination of the Logan (1999) tropospheric climatology with the Fortuin and Kelder (1998) strato25 spheric climatology. The standard deviations of the normalized differences, expressed as percentages, are then computed over the globe and aggregated over latitude bands of $30^{\circ}$, except for the equatorial region where they are averaged over a larger band of 60 degrees. The results are analysed only between the surface and the $5 \mathrm{hPa}$ level

High resolution assimilation

B. Pajot et al.

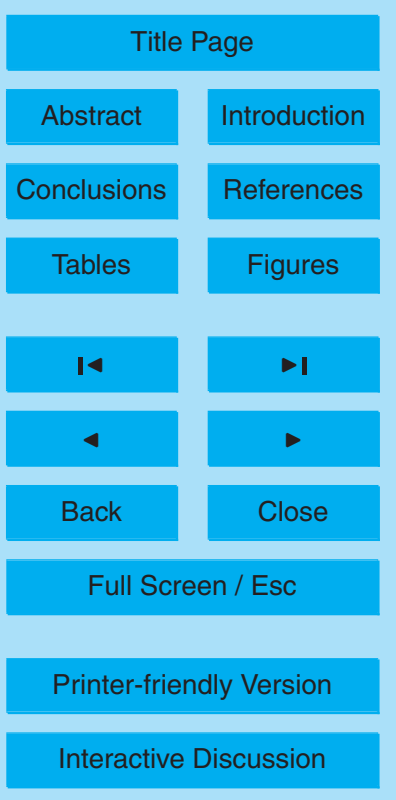


since ozonesondes have large errors above that level. Unfortunately, for the period under study, ozone soundings were unavailable for the latitude band $\left[60^{\circ} \mathrm{N}: 90^{\circ} \mathrm{N}\right]$.

\section{Production of the ozone analysis}

Our objective is to characterize the benefits brought to the ozone assimilation of (i) 5 increasing the CTM horizontal resolution and (ii) increasing the super-observations resolution. Therefore we carried out different assimilation experiments where only the parameters linked to these aspects are modified. The next sections describe the assimilation system, the way we create the two datasets, and the numerical simulations. Then the system consistency is evaluated.

\section{$10 \quad 3.1$ The assimilation system}

\subsubsection{The MOCAGE CTM}

The CTM used in this study is the MOCAGE model (Peuch, 1999). For most recent MOCAGE applications, the global horizontal grids are the Gaussian T42 one or the regular $2^{\circ} \times 2^{\circ}$ one. In this study, we selected the Gaussian T42 grid and we developed is the same as the one used in the ECMWF ERA-Interim reanalyses.

The T170 version of MOCAGE becomes numerically costly with a full chemistry scheme. As we are only interested in the ozone distribution, and to save time in our computation, we use the linear ozone parametrisation developed by Cariolle and 20 Teyssèdre (2007). Combined with the assimilation of stratospheric measurements, this parametrisation produces results that compare well with more comprehensive chemistry schemes (Geer et al., 2006).

Until now, most of our studies with MOCAGE used the ECMWF operational analyses as the meteorological fields that force the CTM. These analyses are computed
11, 29357-29406, 2011

\section{High resolution assimilation}

B. Pajot et al.

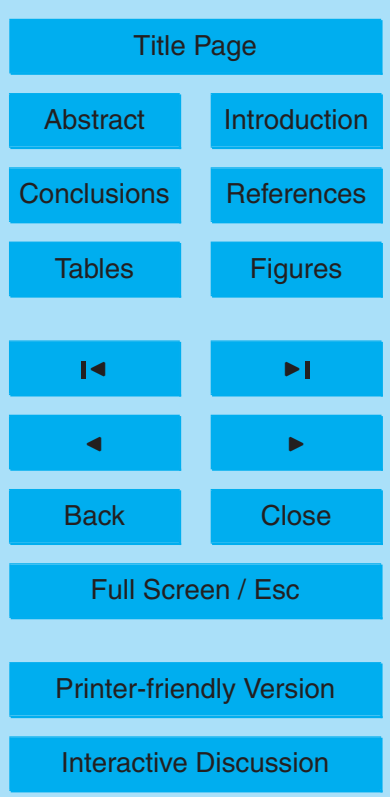


on a N800 reduced Gaussian grid. It turns out that, for the period under study, the ECMWF operational analyses suffer from a lack of dissipation at the smallest resolved scales. When they are truncated at the T170 resolution, we observe that too much energy remains in the small scales of the dynamical fields. As a consequence, using 5 the truncated dynamical fields from the ECMWF operational analyses in the T170 configuration of MOCAGE produced unrealistic noisy ozone fields. This problem has not been encountered when using the ERA-Interim reanalyses as they are produced on a grid similar to the T170 one. So, in this study, the meteorological fields are derived from the ERA-Interim reanalyses.

10 As a CTM, MOCAGE works with a linear time interpolation between two forcing steps. This procedure is adequate for the large-scale planetary waves, but we observe that when the time gap between two steps is too large the propagation of the smallscale waves is not well represented. With the high resolution CTM, we compute the linear time interpolation between two meteorological fields separated by $3 \mathrm{~h}$ (instead 15 of the usual $6 \mathrm{~h}$ ). This frequency update prevents excessive noise developing in our ozone simulations.

\subsubsection{The Valentina assimilation system}

The Valentina assimilation system has already been used to assimilate the IASI ozone columns combined with the MLS ozone profiles (Massart et al., 2009). The version of Valentina adopted for the present study is mostly similar to the one used in Massart et al. (2011) where the assimilation algorithm is incremental 4D-Var (Courtier et al., 1994). Our version of the 4D-Var algorithm accounts for the ozone transport by dynamics in the assimilation process but not the chemistry. With this configuration, the 4D-Var assimilation window is set at $12 \mathrm{~h}$.

25 To run Valentina with the T170 version of MOCAGE, Valentina had to be adapted to support the increase resolution of the control space. The main change was to carry out the assimilation process in the spectral space despite the CTM being discretized in the physical space. With this modification the size of the control vector is reduced.

\section{ACPD}

11, 29357-29406, 2011

\section{High resolution assimilation}
B. Pajot et al.

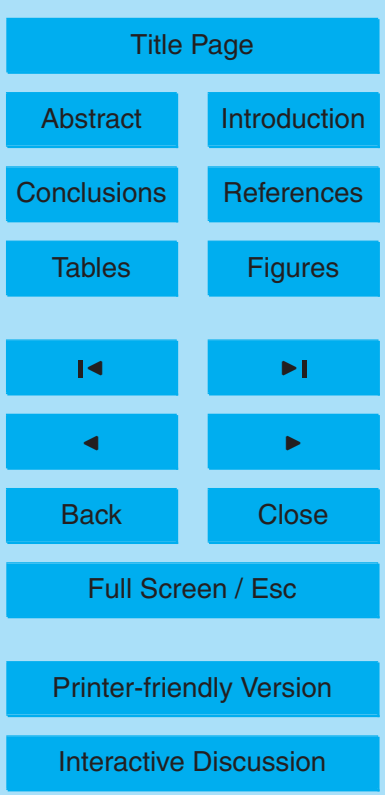


In the Valentina assimilation system, the forecast error covariance matrix is split into a correlation matrix and a diagonal matrix populated with the forecast error variance (square of the forecast error standard deviation). The forecast error standard deviation is expressed in the physical space. Its value for September comes from the study of 5 Massart et al. (2011) where it is estimated from an ensemble of assimilation simulations. The estimate of the standard deviation matrix was provided on a $2^{\circ} \times 2^{\circ}$ grid, and interpolated onto the targeted grid, i.e. T42 or T170.

Following Massart et al. (2011), we assume that the relative values of the background error standard deviation matrix are correct and that a global bias may appear. So we 10 apply diagnostics like those of Desroziers et al. (2005) to determine a multiplicative correction factor, i.e. $s_{\mathrm{b}}$. In our configuration a value of about ten was found for $s_{\mathrm{b}}$. Thus we multiplied the background error standard deviation estimates by $s_{\mathrm{b}}$, giving what we hereafter refer to as an effective standard deviation. Figure 1 shows that on average the effective standard deviation on the T42 grid is higher in the UTLS region 15 with values between $20 \%$ and $30 \%$. Below, in the troposphere, the effective standard deviation is very low. In the stratosphere, the effective standard deviation is higher over the NPR and the Southern Polar Region (SPR) with values between $9 \%$ and $15 \%$. Elsewhere, the effective standard deviation is rather homogeneous. The shape of the zonal mean of the effective standard deviation is the same for the T170 grid. So, whatever the grid resolution, the assimilation process gives less confidence to the model in the UTLS and over the polar regions in the stratosphere than in the other parts of the atmosphere.

The background error correlation matrix is divided into a horizontal and a vertical operator, both modelled using a diffusion equation (Weaver and Courtier, 2001). We apply a homogeneous horizontal correlation length-scale to apply on the correlation operator. Thus, the correlation operator corresponds in the spectral space to the multiplication of the control vector by a diagonal matrix. The horizontal length-scales are set to $275 \mathrm{~km}$ (that corresponds to $2.5^{\circ}$ at the equator) for the T42 IASI \& MLS assimilation. As shown in Bouttier (1994), the horizontal length-scales decrease in areas
High resolution assimilation

B. Pajot et al.

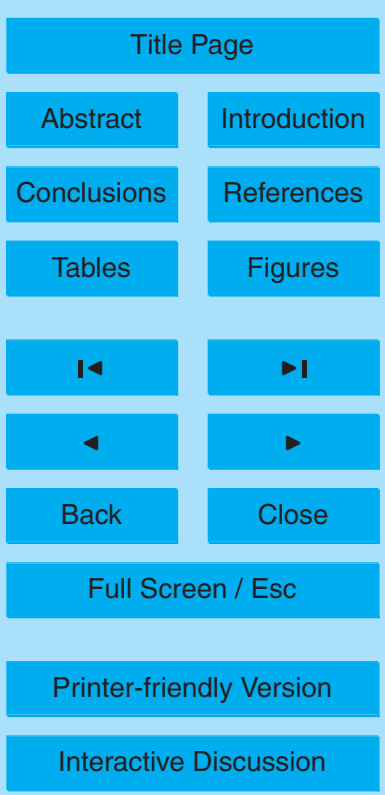

29369 
with dense observations, so we choose to set the horizontal length-scales to $77 \mathrm{~km}$ (that corresponds to $0.7^{\circ}$ at the equator) for the T170 IASI \& MLS assimilation. For our control vector expressed in the spectral space, we compute the diffusion tensor from the length-scale value and the normalization according to Pannekoucke and Massart 5 (2008). The vertical correlation length-scales are diagnosed from the same ensemble of assimilation runs as the variances and thus vary with location.

With MLS, the random observation error of one level over a profile is assumed to be independent of the random observation error of the other levels along the same profile and of levels over other profiles. This means that there is no spatial nor temporal 10 correlation of the observation error. We also assume that IASI super-observations are uncorrelated with time. With these choices the observation error covariance matrix is diagonal.

\subsection{Combined MLS and IASI datasets}

Compared with MLS data, IASI data possess several interesting features. The IASI 15 instrument has an excellent horizontal coverage due to the MetOp-A satellite polar orbit and its capability to scan across track over a swath width of $\sim 2200 \mathrm{~km}$. It brings information all over the globe, in particular over the poles whereas the MLS instrument does not make any measurement poleward of $82^{\circ}$. IASI measures every $50 \mathrm{~km}$ at nadir when the separation between two MLS scans is $1.5^{\circ}$ (about $165 \mathrm{~km}$ ). In addition the

20 total ozone columns from IASI give information for all over the vertical, in particular in the troposphere where little information is given by the MLS measurements.

Following Massart et al. (2009), the statistics for the IASI measurement errors are first derived by the assimilation of the MLS data with both the T42 and T170 configurations of MOCAGE. Then, for each IASI measurement, we compute their differences 25 with the total ozone columns computed from the analysis of the MLS data, and we grid these differences on the T42 or T170 grid. We then assume that the average of the differences is due to a bias that is attributed to the IASI columns. This bias could come from the different methods of the measuring devices (in the IR for IASI and in the

High resolution assimilation
B. Pajot et al.

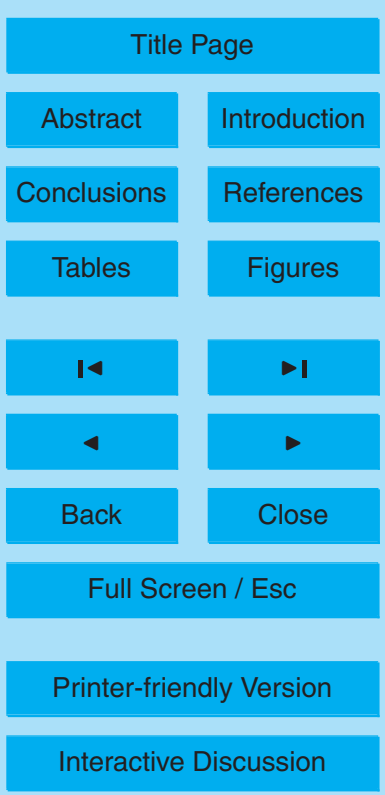


microwave for MLS) and from the way the model spreads the column content information within the vertical. We also assumed that the standard deviation of the differences is the standard deviation of the IASI measurement error.

After removing the diagnosed bias from the IASI measurements gridded on the T42 5 or T170 grid, and after assigning a standard deviation to the IASI measurement error, we assimilate the T42 IASI data with the T42 configuration and the T170 IASI data with the T170 configuration. A posteriori diagnostics similar to those of Desroziers et al. (2005) are used to adjust the mean value of the standard deviation of the observation error and take into account the representativeness error (see Massart et al., 2011, for 10 details on the use of a posteriori diagnostics). In particular we assume that the standard deviation of the observation error has the same shape than the standard deviation of the measurement error, and that there is a multiplicative factor of $\sim 2$ between them that is given by the a posteriori diagnostics.

We then verify that the total ozone columns computed from the MLS analyses and 15 from the IASI analyses are unbiased in both configurations (T42 and T70). Thus we could combine the data, assuming that the IASI and the MLS observation errors are not correlated.

\subsection{The numerical experiments}

As detailed previously, we have two configurations of MOCAGE, and two sets of com20 bined MLS and IASI data. Several combinations of the model and the data resolution have therefore been used to assess the relative impact of the model and the data resolutions. In a first step, we have produced ozone fields with direct model simulations (without any assimilation) at the T42 and T170 horizontal resolutions. They are, respectively referred to as $\mathrm{Ml}$ and $\mathrm{Mh}$, where the first letter $\mathrm{M}$ stands for MOCAGE, and

\section{ACPD}

11, 29357-29406, 2011

\section{High resolution assimilation}

B. Pajot et al.

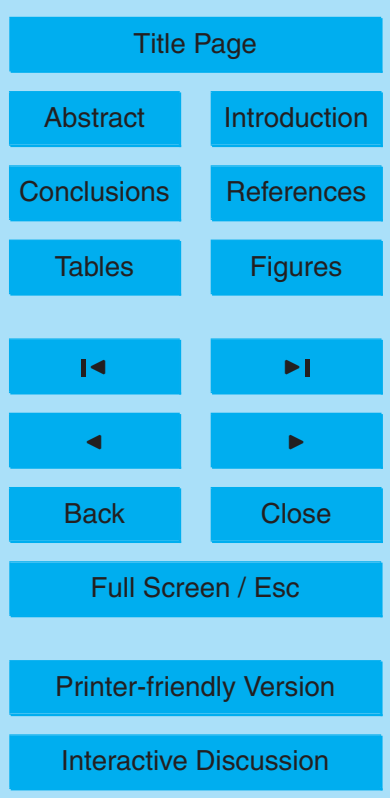
to assess the impact of the model horizontal resolution change without data assimilation, and they also produce a reference from which the impact of the assimilation can be evaluated. 
In a second step, we have assimilated the observation set at the T42 resolution with the two model versions and the observation set at the T170 resolution with the high resolution model version. These experiments are referred to as All, Ahl and Ahh, where the first letter A stands for Assimilation, the second letter I or $h$ stands for the 5 MOCAGE resolution, and the third letter I or $h$ means that the data used are at the lowest or highest resolution. The comparison between All and Ahl experiments gives the impact on the analysis of using the CTM at high resolution, and the comparison between Ahl and Ahh gives the impact of increasing the data horizontal resolution.

The experiments are summarized in Table 2, which gives for each experiment the 10 horizontal resolution of the CTM, the assimilated dataset and the horizontal correlation length-scale. In the various figures presented thereafter, the results are plotted, respectively in green, red and blue for the All, Ahl and Ahh experiments.

The period under study covers the month of September 2008 after a 15 days spin-up period. The initial global ozone concentrations for the 15 of August 2008 were taken 15 from a previous assimilation of MLS data generated on a $2^{\circ} \times 2^{\circ}$ regular horizontal grid. This initial condition was interpolated onto the T42 and T170 grids.

To determine whether or not an observation is consistent with the model, a rejection threshold for the observations is set to $10 \%$ of their difference with the background field projected into the observational space for the three assimilation experiments. Thus, around $2 \%$ of the observations are discarded, with around $13 \%$ of the MLS observations and less than $1 \%$ of the IASI observations (for either super-observations dataset).

\subsection{Consistency diagnostics}

In order to check the consistency of all our analyses, Fig. 2 shows statistical a posteriori diagnostics. The upper panel represents the variations of the cost function at the minimum divided by half the number of assimilated observations for the month of September. This is known as the $\chi^{2}$ validation diagnostics. As shown in Desroziers and Ivanov (2001), this diagnostic should approach 1 if the information error covariances are properly specified. The plotted values are close to 1 for the Ahh experiment,

High resolution assimilation

B. Pajot et al.

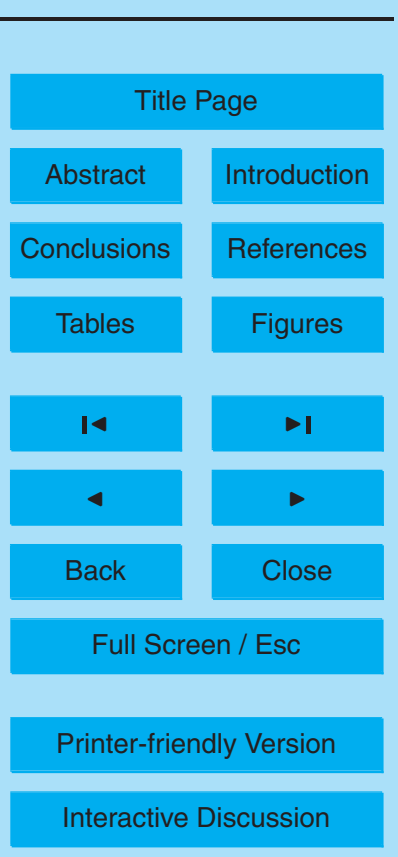


which means that the Ahh experiment is well configured. They are greater than 1 for the All experiment, which means that too much confidence has been put in the model or in the observations. And they are lower than 1 for the Ahl experiment, which means that not enough confidence has been put in the model or in the observations. Note 5 that during the lack of IASI data from 16 to 20 September, all values diverge from the optimal value of 1 .

To complete this information, the middle and lower panels of Fig. 2 represent other diagnostics introduced by Desroziers et al. (2005). Based on the combinations of assimilated observations minus background, assimilated observations minus analysis, 10 and background minus analysis, multiplicative correction coefficients $s_{\mathrm{o}}$ and $s_{\mathrm{b}}$ are computed. Their square should be applied to $\mathbf{R}$ and $\mathbf{B}$, the covariances matrix of the observations and forecasts error (that is the calculations $s_{\mathrm{o}}^{2} \mathbf{R}$ and $s_{\mathrm{b}}^{2} \mathbf{B}$ ). $s_{\mathrm{o}}$ or $s_{\mathrm{b}}$ greater (lower) than 1 means that less (more) confidence should be put in the observations or in the model.

15 Figure 2 shows that $s_{0}$ coefficients are close to 1 for all experiments, which means that observation errors have been correctly specified. $s_{0}$ values are greater than 1 during the five consecutive days without IASI observations with the three experiments, which means that less confidence should be put in the observations constructed with MLS data only during that period. Figure 2 also shows with the plot of the $s_{\mathrm{b}}$ coefficients that less confidence should be given to the model for All assimilation (with values greater than 1 for the green line). This is consistent as the T42 lower horizontal resolution is used. For Ahl and Ahh experiments, the confidence in the model should be slightly greater. Overall these diagnostics show that our assimilation system is well configured.

25 To assess the benefits brought by the model horizontal resolution with and without assimilation, the resulting ozone fields are now intercompared and compared to independent data.
ACPD

11, 29357-29406, 2011

\section{High resolution assimilation}

B. Pajot et al.

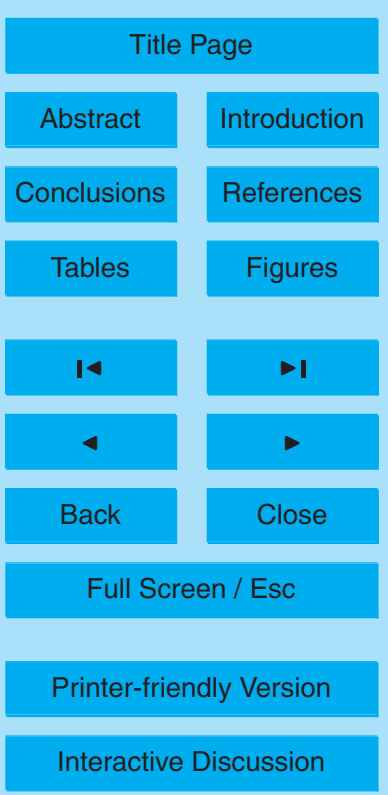




\section{Impact of the model resolution}

In this section, we first compare the ozone products from the Ml and Mh MOCAGE simulations at the two horizontal grid resolutions. With this comparison we characterize the effect of increasing the model resolution without any assimilation. Then we look at

5 the All and Ahl data assimilations at the two horizontal grid resolutions.

\subsection{The free run simulations}

\subsubsection{The impact of increasing resolution}

In order to know if the experiment with the T170 horizontal grid modifies the large scale structures of the ozone fields, we compute the energy spectra of the total ozone 10 columns from the $\mathrm{Mh}$ and $\mathrm{Ml}$ experiments, that we, respectively call $\boldsymbol{e}_{\mathrm{h}}$ and $\boldsymbol{e}_{\mid}$. We then diagnose the monthly average of the daily differences between $\boldsymbol{e}_{\mathrm{h}}$ and $\boldsymbol{e}_{\mathrm{l}}$, that we denote $\overline{\boldsymbol{e}_{\mathrm{h}}-\boldsymbol{e}_{\mathrm{l}}}$, where $\overline{\boldsymbol{e}}$ stands for the monthly average of $\boldsymbol{e}$. We normalize the $\overline{\boldsymbol{e}_{\mathrm{h}}-\boldsymbol{e}_{1}}$ difference by the mean $\left(\overline{\boldsymbol{e}_{\mathrm{h}}}+\overline{\boldsymbol{e}_{\mid}}\right) / 2$. Figure 3 shows the $\overline{\boldsymbol{e}_{\mathrm{h}}-\boldsymbol{e}_{1}}$ normalized difference plotted up to the 42nd wavenumber. Large differences appeared all over the wavenumbers, with values increasing with the wavenumber. This means that the Mh experiment has changed its large scale structures as well as its small scale structures compared to the Ml experiment. The differences are mainly positive, so the fields from the Mh experiment have more wave amplitude compared to those of the $\mathrm{Ml}$ experiment.

\subsubsection{Cross-comparison between the simulations}

20 The differences between the ozone concentrations and the total ozone columns from the $\mathrm{Ml}$ and $\mathrm{Mh}$ experiments are first examined.

Figure 4 shows the zonal difference plus and minus the standard deviation between the total ozone columns from both experiments, normalized by the ERA-Interim reanalyses. Compared to $\mathrm{Ml}$ the Mh simulation produces less ozone between the tropics and 25 more ozone over the poles. The differences are below $2 \%$ over the globe, but reach 29374

High resolution assimilation

B. Pajot et al.

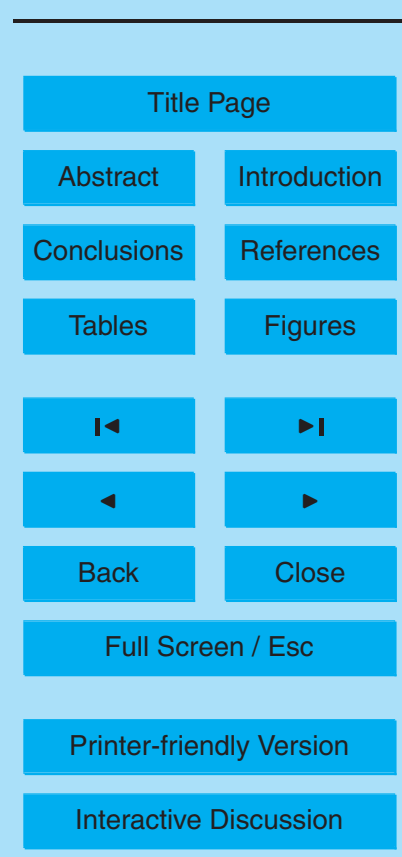


$4 \%$ over the SP. The bias in the total ozone columns is significant at the tropics. At mid and high latitudes the ozone variability increases and the biases are only significant around the latitude $70^{\circ} \mathrm{S}$.

The top panel of Fig. 5 shows the zonal mean of the monthly average of the dif5 ferences between the ozone partial pressures from the $\mathrm{Mh}$ and $\mathrm{Ml}$ experiments as a function of the pressure. In the Mh experiment there is less ozone between $45^{\circ} \mathrm{S}$ and $45^{\circ} \mathrm{N}$ in the troposphere and in the UTLS region and more ozone over the polar regions. This is consistent with the differences found in the total ozone columns as shown in Fig. 4. The highest differences are located over the poles in the UTLS where they exceed $1 \mathrm{mPa}$ whereas they are below $0.5 \mathrm{mPa}$ elsewhere.

The lower panel of Fig. 5 shows the zonal mean of the monthly standard deviation of the differences between the ozone partial pressures from the Mh and Ml experiments. It shows that the variability is mainly located over the troposphere and the UTLS regions. The maximum values are located at the polar vortex boundary between 50 and $100 \mathrm{hPa}$ with values above $1.2 \mathrm{mPa}$, in regions that are more dynamically active.

To further illustrate the differences between the Mh and Ml experiments, Fig. 6 represents the ozone fields centred over the SPR in the middle stratosphere from $\mathrm{MI}$ and Mh experiments (on top at left and at the middle) for September 30 and $55 \mathrm{hPa}$. It can be seen that the ozone hole is already well developed. The shape of the ozone hole is slightly different between the Mh and Ml experiments, and the structures around the ozone hole also differ. As previously discussed the Mh experiment has a higher spatial variability in the ozone fields in regions with large ozone gradients and active dynamics, two characteristics that are encountered at the vortex boundary.

There is a clear impact of an increase of the model horizontal resolution on the ozone distribution in the free run simulations. A large part of the difference comes from the vertical velocity amplitude that is increasing with the model resolution. The vertical velocity possesses strong horizontal gradients and local extrema are smoothed with the low resolution while with the high resolution model most of its small scale characteristics are retained.

High resolution assimilation

B. Pajot et al.

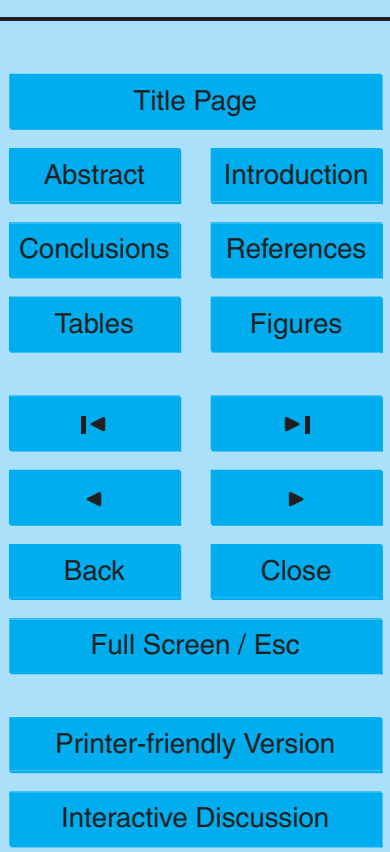

Interactive Discussion 


\subsection{Changes in the analysis}

We examine here the impact of increasing the model resolution on the ozone analysis. To assess the benefits brought by the change of model resolution with the T42 IASI and MLS dataset assimilation, the analyses are compared to independent data. We

5 choose to compare them with another global assimilation system, i.e. the ERA-Interim reanalysis, with profiles from ozonesondes and with total ozone columns from the OMI. When the low resolution model results are compared to the independent datasets (that is done in the physical space), they are projected on the T170 grid. Thus the error of representativeness is the same for all the experiments.

\subsubsection{Diagnostics from the analyses}

As previously done for the Mh and MI MOCAGE simulations, we have computed the energy spectra of the total ozone columns from the Ahl and All experiments, that we, respectively call $\boldsymbol{e}_{\mathrm{hl}}$ and $\boldsymbol{e}_{\|}$. We then computed the monthly average of the daily differences between $\boldsymbol{e}_{\mathrm{hl}}$ and $\boldsymbol{e}_{\|}$, that we note $\overline{\boldsymbol{e}_{\mathrm{hl}}-\boldsymbol{e}_{\|}}$, and normalized them by the mean $15\left(\overline{\boldsymbol{e}_{\mathrm{hl}}}+\overline{\boldsymbol{e}_{\|}}\right) / 2$. Figure 3 shows the $\overline{\boldsymbol{e}_{\mathrm{hl}}-\boldsymbol{e}_{\|}}$normalized difference. The difference is lower compared to the $\overline{\boldsymbol{e}_{\mathrm{h}}-\boldsymbol{e}_{\mid}}$difference. This suggests that the Ahl and All experiments have more common structures than the Mh and Ml experiments have themselves. The differences are significant for the high wavenumbers and are negative. This means that the analyses from the All experiment possess more energy compared to the analyses 20 from the Ahl experiment. But the differences are very low for the small wavenumbers, so the largest structures are similar for the fields from the All and Ahl experiments. This can be directly seen in the fields from the All and Ahl experiments shown in Fig. 6.

Assimilating the T42 IASI \& MLS data produces ozone analyses that agree well with the ozone fields from the ERA-Interim reanalysis at $55 \mathrm{hPa}$ on 30 September, both inside the polar vortex and outside at its boundary (Fig. 6). Strong gradients at the boundary of the polar vortex are present in the ozone fields from the All, Ahl and ERAInterim experiments, whereas they are smoother in the ozone fields from the $\mathrm{Ml}$ and Mh experiments.

\section{High resolution assimilation}

B. Pajot et al.

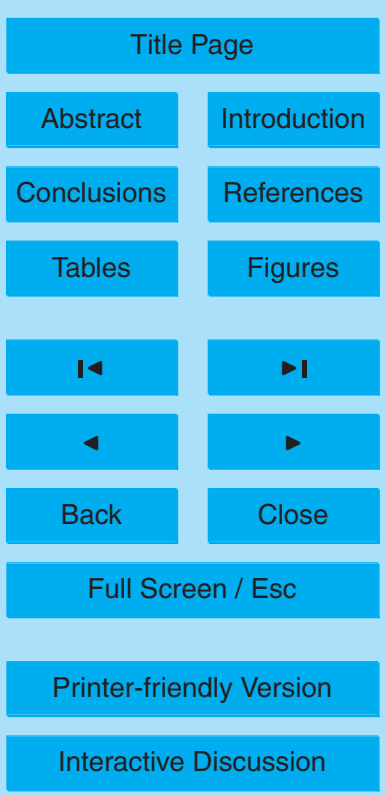




\subsubsection{Comparisons with ERA-Interim reanalysis}

Figure 7 shows that the zonal bias in terms of total ozone columns compared to the ERA-Interim reanalysis is nearly the same for the Ahl and All experiments. This means that the impact of the horizontal grid resolution on the direct model as shown in Fig. 4

5 is partly removed by the assimilation. This is consistent with the very low differences found for the small wavenumbers (Fig. 3). Nevertheless, in the Ahl and All analyses, there is an underestimation of the total ozone columns over the SP and between $20^{\circ} \mathrm{S}$ and $40^{\circ} \mathrm{N}$, the zonal bias reaching $6-7 \%$. Between $80^{\circ} \mathrm{S}$ and $60^{\circ} \mathrm{S}$ and over the $\mathrm{NP}$, the Ahl and All analyses overestimate the total ozone columns compared to ERAInterim reanalyses, the zonal bias reaching 4-5\%. For the standard deviations of the differences with the ERA-Interim reanalyses, Fig. 7 shows that they are largest over the SP with values up to $14 \%$ whereas they are around $5-6 \%$ between $80^{\circ} \mathrm{S}$ and $60^{\circ} \mathrm{S}$ in the polar vortex region, and they do not exceed $4 \%$ elsewhere. The difference between the All and Ahl experiments in terms of standard deviation of the differences with ERA-Interim data does not exceed $1 \%$. The largest differences are located over the poles and at the polar vortex boundary where small scale phenomena, with high variability, occur. There the Ahl experiment is more consistent with the ERA-Interim analysis.

We now look at the characteristics of the vertical variability of the differences between the All and Ahl experiments. We define $\sigma_{\mathrm{hl}}$ as the zonal average of the standard deviation of the differences (Ahl-ERA-Interim) and $\sigma_{\|}$as the zonal average of the standard deviation of the differences (All-ERA-Interim) (both in partial pressure). Figure 8 shows the latitude-pressure distribution of $\sigma_{\mathrm{hl}}-\sigma_{\|}$. In terms of ozone variability, the Ahl experiment has globally a better agreement with the ERA-Interim reanalysis than the All experiment. This is significant in the Northern Hemisphere $(\mathrm{NH})$ poleward of $60^{\circ} \mathrm{N}$ between 300 and $20 \mathrm{hPa}$ and in the Southern Hemisphere $(\mathrm{SH})$ poleward of $30^{\circ} \mathrm{S}$ between $300 \mathrm{hPa}$ and $40 \mathrm{hPa}$. Over the NP, there is the highest enhancement, mainly between $100 \mathrm{hPa}$ and $20 \mathrm{hPa}$. The improvements in the analyses are located in areas with strong ozone gradients and active dynamics with small scale structures.

High resolution assimilation

B. Pajot et al.

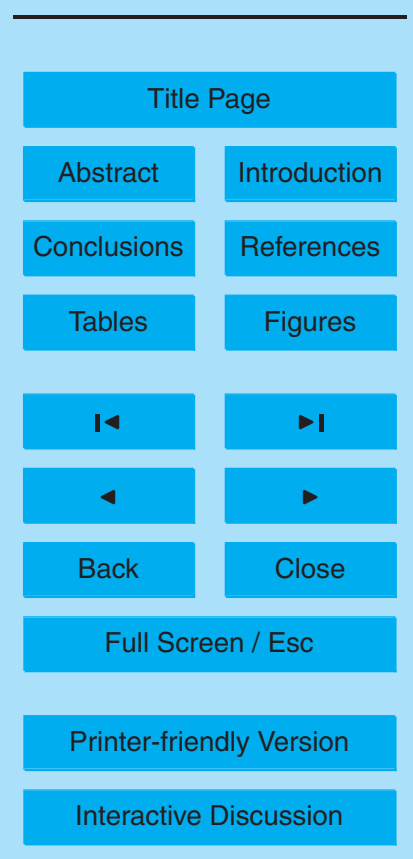

Interactive Discussion 


\subsubsection{Comparisons with ozonesondes}

Figure 9 shows the zonal and monthly average of the standard deviation of the normalized ozone differences between the All and Ahl experiments and the ozonesondes. It also shows the standard deviation of the differences between the Mh experiment 5 and the ozonesondes. The variability of the error of the ozone fields from the $\mathrm{Mh}$ experiment is globally below $20 \%$ above $68 \mathrm{hPa}$ compared to the ozonesondes measurements. This value is of the same magnitude as the measurement error. The error grows below $68 \mathrm{hPa}$ and reaches about $40 \%$ in the UTLS (globally), between 150 and $300 \mathrm{hPa}$. This error below $68 \mathrm{hPa}$ is different for each band of latitude and is particu-

10 larly fluctuating in the $\left[60^{\circ} \mathrm{S}: 30^{\circ} \mathrm{S}\right]$ and $\left[30^{\circ} \mathrm{N}: 60^{\circ} \mathrm{N}\right]$ bands where it reaches its highest variability and its highest values (up to $50 \%$ ).

Globally the Ahl analysis shows a better agreement with ozonesonde variations than the Mh simulation, thus reducing the error up to $10 \%$, especially in the stratosphere but also in the troposphere except near the high latitude tropopause. For example, 15 the error increases by $20 \%$ in the $\left[60^{\circ} \mathrm{S}: 30^{\circ} \mathrm{S}\right.$ ] band near the high latitude tropopause. We already diagnosed a similar behaviour in that region with the assimilation of the MLS data, a result likely due to the larger variability of the MLS data in the UTLS. The information brought by the ozone columns from the T42 IASI data is thus not sufficient to constrain the analysis in this region. The use of the IASI AKs could improve the vertical spreading of the information and could cope with that difficulty.

Compared to ozonesondes the Ahl analysis performs better than the All analysis. But here again, no systematic picture emerges. For example, the All analysis shows an error increase of $15 \%$ at $250 \mathrm{hPa}$ in the [60 S:30 $\mathrm{S}$ ] band compared with the Ahl analysis, whereas the Ahl analysis already has an error increase of $20 \%$ compared to the Mh simulation. But in the $\left[90^{\circ} \mathrm{S}: 60^{\circ} \mathrm{S}\right]$ band, results from the All analysis are better throughout almost all the vertical range.

\section{ACPD}

11, 29357-29406, 2011

High resolution assimilation

B. Pajot et al.

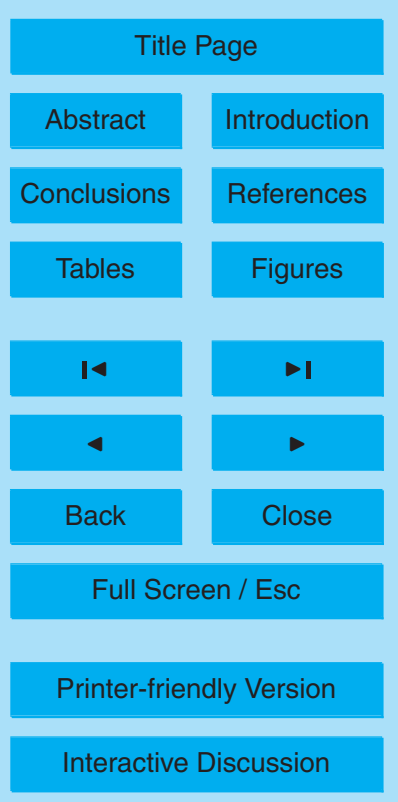




\subsubsection{Comparisons with OMI}

The upper panel of Fig. 10 shows the zonal and monthly bias between each of the $\mathrm{Mh}, \mathrm{All}$ and Ahl experiments and the OMI total ozone columns. Consistent with what has been diagnosed previously, the ozone fields from the Mh experiment have much

5 better agreement with the OMI data than the ozone fields from the Ml experiment. So only the fields from the Mh experiment are plotted. Figure 10 shows that the Mh experiment systematically overestimates the total ozone columns in the high latitudes by $5 \%$ to $20 \%$ and underestimates them between $20^{\circ} \mathrm{S}$ and $40^{\circ} \mathrm{N}$ up to $10 \%$. The assimilation of the T42 IASI \& MLS data reduces significantly the bias everywhere for both configurations of the CTM; the analyses also slightly underestimate the total ozone columns everywhere but the poles. The overestimation over the poles may be due to the absence of MLS data poleward of $82^{\circ} \mathrm{N}$ or $82^{\circ} \mathrm{S}$. One can note that, everywhere but in the SPR, the distribution of the biases is identical to the one obtained by comparison with the total ozone columns from the ERA-Interim reanalyses (shown in Fig. 7).

The lower panel of Fig. 10 shows the zonal and monthly average of the standard deviation of the differences between each of the Mh, All and Ahl experiments and the total ozone columns from OMI. The total ozone columns computed from the Mh experiment deviate by $2 \%$ to $3 \%$ from the OMI ones at most latitudes. The error is however larger between $55^{\circ} \mathrm{S}$ and the SP where it reaches up to $9 \%$. In this region with high ozone variability the All and Ahl analyses show major improvements by reducing the standard deviations by $3 \%$ on average. Over the rest of the globe the All and Ahl analyses provide a slight reduction of the standard deviation, in particular between $30^{\circ} \mathrm{N}$ and $80^{\circ} \mathrm{N}$ where they are reduced by $1 \%$. For the All experiment there is one exception to this improvement located over the NP where the standard deviations are nearly increased by $1 \%$. As for the comparison with the ERA-Interim reanalysis, the difference between the All and Ahl experiments in terms of standard deviation of the differences with $\mathrm{OMI}$ data does not exceed $1 \%$, with largest differences at the polar vortex boundary.

\section{ACPD}

11, 29357-29406, 2011

\section{High resolution assimilation}
B. Pajot et al.

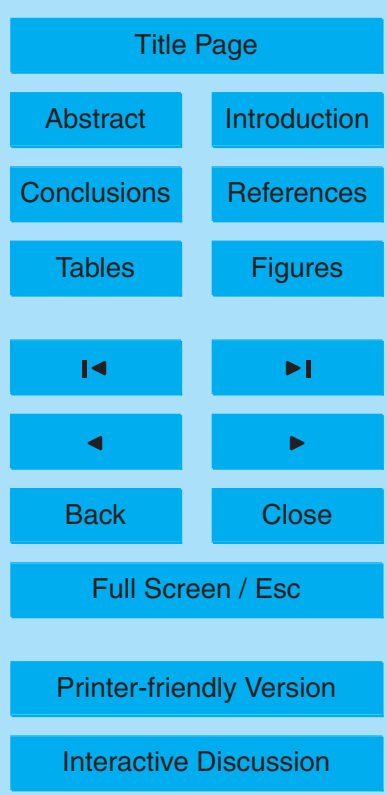




\section{The high resolution analysis}

\subsection{The high resolution experiment}

Table 3 gives the number of IASI observations used to make a super-observation within a model cell for each cell of the T42 and the T170 grids and their variability within the

5 T42 cells, averaged for the month of September and by latitude bands. The standard deviation (in \%) is computed only if there is at least two observations within a cell. The averaged number of IASI observations within a cell decreases from mid latitudes to the poles. For the T42 IASI dataset, the average of the standard deviation is highest between $60^{\circ} \mathrm{S}$ and the SP with an average value of $4.3 \%$ whereas it is around $2.2 \%$ elsewhere. This highest value could be explained by the fact that with this resolution, a cell may contain ozone observations from both sides of the polar vortex edge across which there there are large gradients in the ozone concentration.

When averaging the observations within the T170 model cell instead of the T42 model cell, the number of observations becomes very low with 1 to 2 observations 15 per cell. The IASI observations are close to the model resolution, and the assimilation system should be able to extract the information contained in the IASI data at the lowest resolved scales when they are averaged on the T170 high resolution grid.

For the T42 IASI \& MLS assimilation, we have used a homogeneous value of $275 \mathrm{~km}$ for the horizontal correlation length-scale of the background error. But with such a value 20 for the horizontal correlation length-scale, we are not able to represent the structures that are smaller than this size. This is illustrated by Fig. 11 that displays (from left to right) the total ozone columns fields and increments from the IASI super-observations gridded on the T170 grid and from our Ahh analysis over a sector delimited by the $\left[70^{\circ} \mathrm{S}: 40^{\circ} \mathrm{S}\right]$ latitude band and the $\left[20^{\circ} \mathrm{E}: 60^{\circ} \mathrm{E}\right]$ longitude band on 30 September.

Figure 11a shows that the T170 IASI data accumulated between 00:00 UTC and 12:00 UTC have high spatial variability. This spatial variability is also observed in the total ozone columns field at 00:00 UTC resulting from the Ahh experiment after a $12 \mathrm{~h}$ forecast (Fig. 11b). The simulated field shows fine-scale structures which seem consistent with the observations despite the temporal shift.

High resolution assimilation

B. Pajot et al.

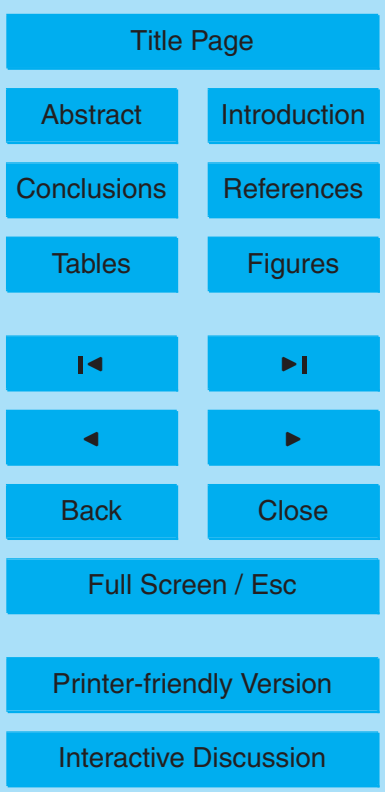


The increment computed at 00:00 UTC, on the T170 grid but with the $275 \mathrm{~km}$ horizontal length-scale, has structures that are too large to account for the fine-scale structures observed in the data (Fig. 11c). The analysis made with the $77 \mathrm{~km}$ horizontal lengthscale (Fig. 11d) shows structures in the increment of the total ozone column that have

5 a size and a shape in better agreement with the model and the super-observation horizontal resolutions.

In this study, we have considered that there is no correlation between the observation errors, and that the horizontal correlation length-scale of the background error is small enough to separate the influence of each observation from the others. In the 10 following, we estimate the impact of using super-observations on a smaller grid size by comparing the Ahl and Ahh experiments with independent observations. As shown in Liu and Rabier (2003), increasing the observation density for this uncorrelated-error case should improve our analysis. Then we look at some results at synoptic scale to further characterize the impact of increasing the observation density.

\subsection{Comparisons with independent observations}

The differences between the zonally averaged total ozone columns from the Ahl and Ahh experiments and the ERA-Interim reanalyses or the OMI data are shown in the upper panels of Figs. 7 and 10. They differ from less than $1 \%$ between $80^{\circ} \mathrm{S}$ and $70^{\circ} \mathrm{S}$. The differences are smaller for the Ahl experiment when compared to OMI data, whereas for Ahh the smallest deviations are found when compared to the ERA-Interim reanalysis. Elsewhere the values of the differences are similar.

As shown in the lower panels of Figs. 7 and 10, the zonal average of the standard deviation between the Ahl experiment and the ERA-Interim and OMI data is different from the one between the Ahh experiment and the ERA-Interim and OMI data. In-

creasing the grid resolution on which IASI observations have been averaged with the $77 \mathrm{~km}$ horizontal correlation length-scale reduces the standard deviations. For the Ahh experiment, compared to the OMI total ozone columns, the error never exceeds $5 \%$ in the SPR, and compared to the ERA-Interim reanalyses the error is lower than $5 \%$ in the SPR everywhere but beyond $80^{\circ} \mathrm{S}$.

\section{ACPD}

11, 29357-29406, 2011

\section{High resolution assimilation}
B. Pajot et al.

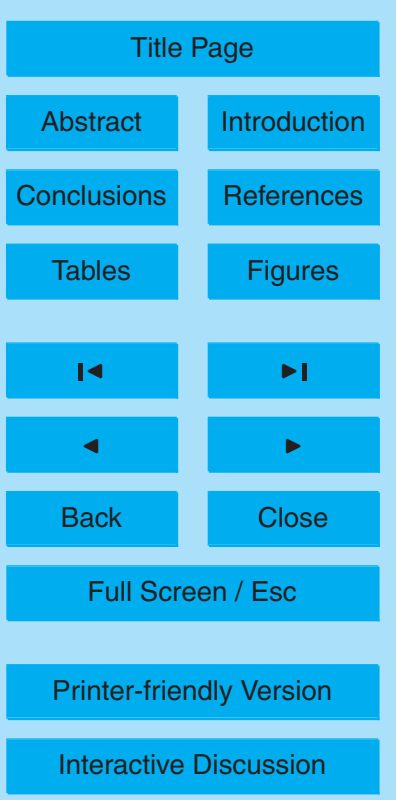


Figure 9 shows that the fields from the Ahh and Ahl experiments agree to the same order with the ozonesondes over most of the vertical range. But the error is slightly increased between 10 and $30 \mathrm{hPa}$. It suggests that the information coming from the T170 IASI dataset has not been correctly distributed in the vertical.

\section{$5 \quad 5.3$ Results at synoptic scale}

Figure 6 shows that the ozone field from the Ahh experiment at $55 \mathrm{hPa}$ shows smallscale structures that have shapes that are not present in the ERA-Interim reanalysis and the Ahl experiment. In addition, the ozone concentration inside the polar vortex is slightly higher for the Ahh experiment than for the Ahl experiment and the ERA-Interim reanalysis. The ozone concentration inside the largest structures surrounding the polar vortex are also lower than for the Ahh experiment. As a result, the horizontal ozone gradient at the polar vortex boundary is smoother for the Ahh experiment. The similarity at $55 \mathrm{hPa}$ between the ERA-Interim reanalysis and the Ahl experiment is likely due to the assimilation of the MLS data in both experiments, and the difference compared to the Ahh experiment comes from the decrease of the correlation horizontal length scale which reduces the influence of MLS data on the Ahh analyses.

These changes of the ozone concentrations at $55 \mathrm{hPa}$ are illustrated in the top panels of Fig. 12. They represent the ozone volume mixing ratio from latitude $50^{\circ} \mathrm{S}$ to the $\mathrm{SP}$ along the longitudes $60^{\circ} \mathrm{W}$ (at left) and $120^{\circ} \mathrm{E}$ (at right) for the Mh, Ahl and Ahh 20 experiments and the ERA-Interim reanalysis. Along the $90^{\circ} \mathrm{W}$ longitude the Ahh and Ahl analyses are in good agreement with the ERA-Interim analysis, and show an improvement over the Mh simulation which significantly underestimate the ozone inside the polar vortex. But along the $120^{\circ} \mathrm{E}$ longitude the Ahh simulation is not doing better than the Mh simulation and degrades the results compared to the Ahl analyses.

25 The same plots are made for the total ozone columns on the lower panels of Fig. 12. The difference visible between the Ahl and Ahh experiments at $55 \mathrm{hPa}$ (Fig. 6) is no longer present when considering the total column. The Ahl and Ahh analyses agree very well with ERA-Interim and show a real improvement compared to the Mh

\section{ACPD}

11, 29357-29406, 2011

High resolution assimilation

B. Pajot et al.

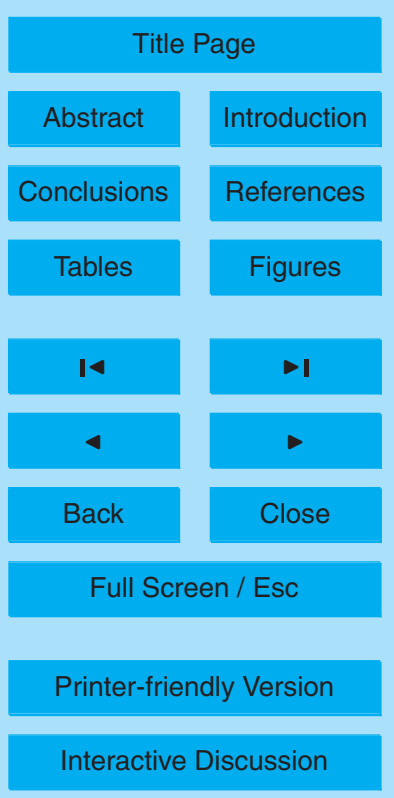


simulation. However the vertical distribution of ozone is quite different in Ahh from Ahl. The Ahl results are closer to the ERA-Interim analyses. The number of vertical soundings is not sufficient to determine which analysis is the best.

\subsection{Relative weight of the observations}

5 The results found in the two previous sections suggest that the information coming from the T170 IASI dataset has not been sufficiently constrained by the MLS ozone profiles. When assimilating the T170 IASI data instead of the T42 IASI data, we multiplied by about 5 the number of assimilated data coming from the IASI instrument as shown in Table 1. With the decrease of the horizontal correlation length-scale with increasing 10 resolution many cells of the model have not used any MLS profile in the Ahh analysis since the horizontal resolution of MLS is much lower than the IASI one. Thus in the Ahh experiment, for many cells of the model the ozone distribution is no longer constrained by the T170 IASI \& MLS dataset but only by the T170 IASI data.

Figure 13 shows the zonal and monthly averaged difference between the ozone partial pressure from the Ahl and Ahh experiments. The differences are much larger than the ones found between the Mh and $\mathrm{Ml}$ experiments (shown in Fig. 5). As the comparison with the ERA-Interim reanalysis and the OMI data showed that the total ozone columns from the Ahl and Ahh experiments are similar, the differences on Fig. 13 confirm that the the constraint on the vertical distribution given by the MLS data is less efficient in the Ahh data assimilation. The vertical ozone distribution has thus been deteriorated by the increase of density of the ozone columns. To cope with this problem the solution is likely to involve using the IASI AKs.

\section{Conclusions}

From a version of the MOCAGE CTM on the T42 horizontal Gaussian grid, we have developed a new version on the T170 grid. We have adapted our Valentina assimilation
11, 29357-29406, 2011

\section{High resolution assimilation}

B. Pajot et al.

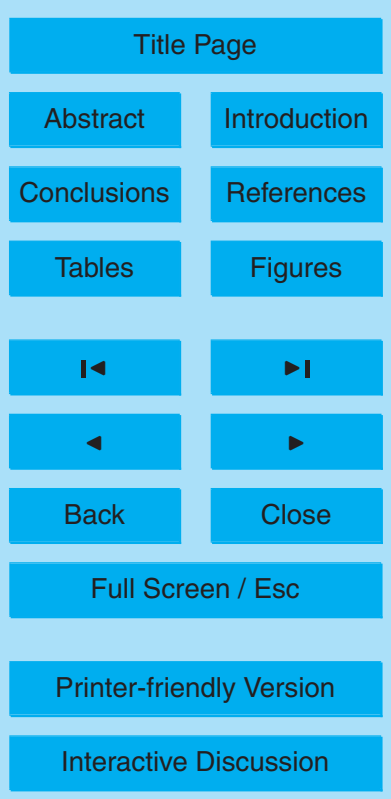


system to work in the spectral space and to reduce the numerical cost due to the increase of the horizontal resolution. We have combined the MLS and the IASI ozone data to make two super-observations datasets at T42 and T170 resolutions.

The direct simulations of MOCAGE for the month of September 2008 show that the 5 increase of the horizontal resolution modifies the simulated ozone concentrations not only at the smallest scales but also at the largest scales. Moreover, the horizontal resolution may influence by more than $1 \mathrm{mPa}$ the ozone concentration, mainly in the UTLS, and by more than $5 \%$ the total ozone columns, mainly over the NPR and the SPR. These modifications are linked to a better representation of the vertical velocities 10 within the T170 configuration.

With the assimilation of the T42 IASI \& MLS dataset the increase of the CTM horizontal resolution showed a mainly positive but small influence on the ozone analyses. The differences, compared to the ERA-Interim reanalysis or to the OMI data, between the total ozone columns from the Ahl and All experiments are very small (lower than $1 \%$ ) 15 . Nevertheless the resolution increase brings a better agreement with the ERA-Interim ozone concentrations in terms of variability. For the comparison with the ozonesondes, results are globally slightly better but are deteriorated at some vertical vertical levels.

Finally, assimilating the T170 IASI dataset improves the variability of the total ozone columns compared to the ERA-Interim reanalysis and the $\mathrm{OMI}$ data in the [ $90^{\circ} \mathrm{S}: 60^{\circ} \mathrm{S}$ ] latitude band. The horizontal correlation length-scale of the background error has to be adapted to represent the small-scale structures present in the observations. But this change of the horizontal correlation length-scale reduces the influence of the MLS data compared to the new and finer T170 IASI data. Thus the information coming from the T170 IASI data are not sufficiently constrained in the vertical. Also, the horizontal gradient of the ozone concentrations at the polar vortex boundary at $55 \mathrm{hPa}$ is smoother than with the ERA-Interim reanalysis or with the Ahl experiment. The zonal difference between the ozone partial pressure from the Ahl and Ahh experiments shows significant differences in the ozone fields that are not restricted to the $55 \mathrm{hPa}$ pressure level but spans over the middle stratosphere. This result points out the need to have a source

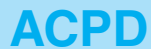

11, 29357-29406, 2011

High resolution assimilation

B. Pajot et al.

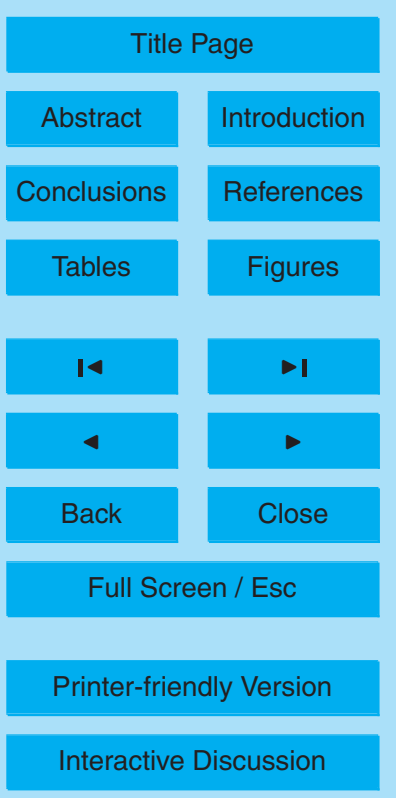

29384 
of information on the vertical ozone distribution that is as dense as the total column dataset assimilated. In our configuration the MLS data is too coarse compared to the IASI data, and the use of IASI AKs appears unavoidable.

To further improve the assimilation one could also consider the use of anisotropic 5 and inhomogeneous horizontal length-scales to better extract the high resolution information within the observations. Our framework is also well suited for further high resolution related developments as, for instance, multi-incremental 4D-Var. This could be combined with an adaptive pre-conditionning, working in a successive manner on a T42 low resolution model grid, then on a T85 intermediate one and finally on the 10 targeted T170 high resolution one.

Finally, we have concentrated our analysis on a limited period of time (the month of September). We plan to extend our assimilation period to cover several years in order to verify that our conclusions are still valid for other seasons, and to characterize the interannual variability of our analyses.

15 Acknowledgements. B. Pajot was supported by a grant from the Fondation d'Entreprise EADS (http://www.fondation.eads.net/fr).

For W. A. Lahoz, this work was funded by the RTRA/STAE (project POGEQA) funded by Région Midi-Pyrénées, and an internal project at NILU.

P. F. Coheur is Research Associate (Chercheur Qualifié) with F. R. S.-FNRS. The research 20 in Belgium was funded by the F. R. S.-FNRS, the Belgian Sate Federal Office for Scientific, Technical and Cultural Affairs and the European Space Agency (ESA-Prodex arrangements). Financial support by the 'Actions de Recherche Concertées' (Communauté Française de Belgique) is also acknowledged.

Thanks to Brice Barret from the Laboratoire d'Aérologie (LA) for the ozonesondes data pro25 cessing.

IASI has been developed and built under the responsibility of the Centre National d'Etudes Spatiales (CNES, France). It is flown onboard the Metop satellites as part of the EUMETSAT Polar System.

The development of the Valentina assimilation system has benefited from the support of the

\section{High resolution assimilation}

B. Pajot et al.

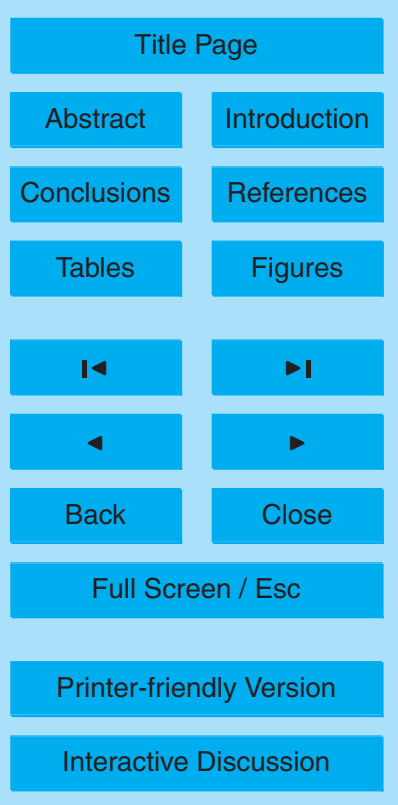

Interactive Discussion 
The publication of this article is financed by CNRS-INSU. (http://ether.ipsl.jussieu.fr).

\section{References}

5 Allen, D., Pickering, K., Duncan, B., and Damon, M.: Impact of lightning NO emissions on North American photochemistry as determined using the Global Modeling Initiative (GMI) model, J. Geophys. Res., 115, D22301, doi:10.1029/2010JD014062, 2010. 29359

Balis, D., Kroon, M., Koukouli, M. E., Brinksma, E. J., Labow, G., Veefkind, J. P., and McPeters R. D.: Validation of Ozone Monitoring Instrument ozone total column measurements using Brewer and Dobson spectrophotometer ground-based observations, J. Geophys. Res., 112, D24S46, doi:10.1029/2007JD008796, 2007. 29365

Berrisford, P., Dee, D., Fielding, K., Berrisford, P., Dee, D., Fielding, K., Fuentes, M., Kallberg, P., Kobayashi, S., and Uppala, S.: The ERA-Interim archive, version 1.0, in: ERA report series, available at: http://www.ecmwf.int/publications/library/ecpublications/_pdf/era/ era_report_series/RS_1.pdf (last access: October 2011), 2009. 29364

Bouttier, F.: A dynamical estimation of forecast error covariances in an assimilation system, Mon. Weather Rev., 122, 2376-2390, 1994. 29369

Buis, S., Piacentini, A., and Déclat, D.: PALM: A Computational framework for assembling high performance computing applications, Concurr. Comp. Pract. E., 18, 247-262, 2006.

Cariolle, D. and Teyssèdre, $\mathrm{H}$.: A revised linear ozone photochemistry parameterization for use in transport and general circulation models: multi-annual simulations, Atmos. Chem. Phys., 7, 2183-2196, doi:10.5194/acp-7-2183-2007, 2007. 29367

Clarisse, L., R'Honi, Y., Coheur, P.-F., Hurtmans, D., and Clerbaux, C.: Thermal infrared nadir observations of 24 atmospheric gases, Geophys. Res. Lett., 38, L10802, doi:10.1029/2011GL047271, 2011. 29362

\section{High resolution assimilation}

B. Pajot et al.

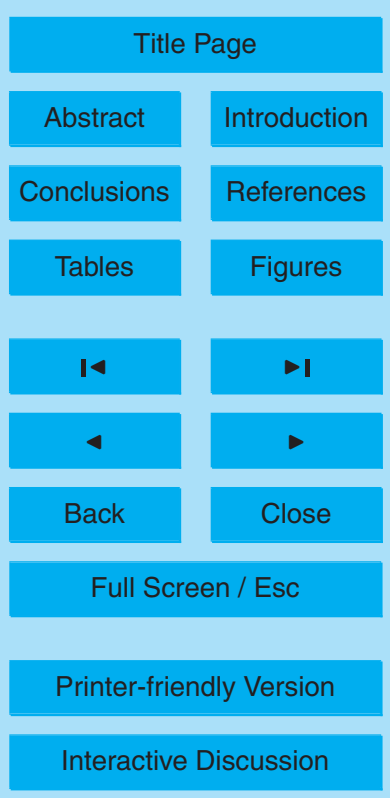


Clerbaux, C., Boynard, A., Clarisse, L., George, M., Hadji-Lazaro, J., Herbin, H., Hurtmans, D., Pommier, M., Razavi, A., Turquety, S., Wespes, C., and Coheur, P.-F.: Monitoring of atmospheric composition using the thermal infrared IASI/MetOp sounder, Atmos. Chem. Phys., 9, 6041-6054, doi:10.5194/acp-9-6041-2009, 2009. 29360, 29362

5 Courtier, P., Thépaut, J.-N., and Hollingsworth, A.: A strategy for operational implementation of 4D-Var, using an incremental approach, Q. J. Roy. Meteor. Soc., 120, 1367-1387, doi:10.1002/qj.49712051912, 1994. 29368

Dee, D. P., Uppala, S. M., Simmons, A. J., Berrisford, P., Poli, P., Kobayashi, S., Andrae, U., Balmaseda, M. A., Balsamo, G., Bauer, P., Bechtold, P., Beljaars, A. C. M., van de Berg, L., Bidlot, J., Bormann, N., Delsol, C., Dragani, R., Fuentes, M., Geer, A. J., Haimberger, L., Healy, S. B., Hersbach, H., Hólm, E. V., Isaksen, L., Kallberg, P., Köhler, M., Matricardi, M., McNally, A. P., Monge-Sanz, B. M., Morcrette, J.-J., Park, B.-K., Peubey, C., de Rosnay, P., Tavolato, C., Thépaut, J.-N., and Vitart, F.: The ERA-Interim reanalysis: configuration and performance of the data assimilation system, Q. J. Roy. Meteor. Soc., 137, 553-597, 15 doi:10.1002/qj.828, 2011. 29365

Desroziers, G., Berre, L., Chapnik B., and Poli, P.: Diagnosis of observation, background and analysis-error statistics in observation space, Q. J. Roy. Meteor. Soc., 131, 3385-3396, 2005. 29369, 29371, 29373

Desroziers, G. and Ivanov, S.: Diagnosis and adaptive tuning of information error parameters in a variational assimilation, Q. J. Roy. Meteor. Soc., 127, 1433-1452, 2001. 29372

Dragani, R.: On the quality of the ERA-Interim ozone reanalysis: comparisons with satellite data, Q. J. Roy. Meteor. Soc., 137, 1312-1326, doi:10.1002/qj.821, 2011. 29364

Dufour, G., Eremenko, M., Griesfeller, A., Barret, B., Dufour, G., Eremenko, M., Griesfeller, A., Barret, B., LeFlochmoën, E., Clerbaux, C., Hadji-Lazaro, J., Coheur, P.-F., and Hurtmans, D.: Validation of three different scientific ozone products retrieved from IASI spectra using ozonesondes, Atmos. Meas. Tech. Discuss., 4, 5425-5479, doi:10.5194/amtd-4-5425-2011, 2011. 29362

Errera, Q., Daerden, F., Chabrillat, S., Lambert, J. C., Lahoz, W. A., Viscardy, S., Bonjean, S., and Fonteyn, D.: 4D-Var assimilation of MIPAS chemical observations: ozone and nitrogen dioxide analyses, Atmos. Chem. Phys., 8, 6169-6187, doi:10.5194/acp-8-6169-2008, 2008. 29359

Fortuin, J. P. F. and Kelder, H.: An ozone climatology based on ozonesonde and satellite measurements, J. Geophys. Res., 103, 709-734, 1998. 29366

\section{ACPD}

11, 29357-29406, 2011

\section{High resolution assimilation}

B. Pajot et al.

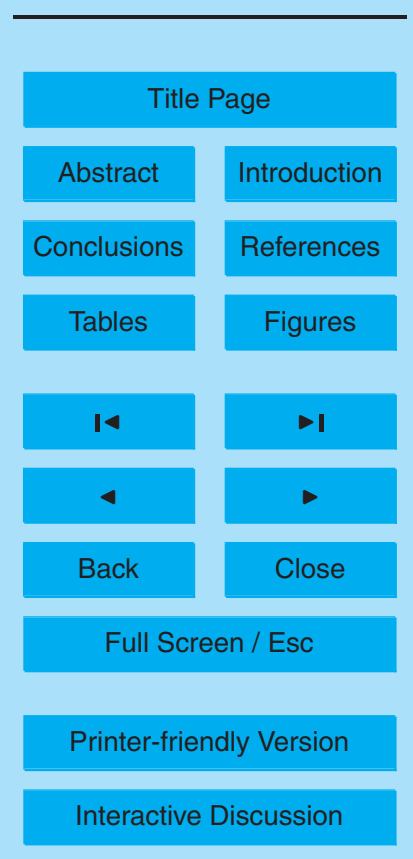


Froidevaux, L., Jiang, Y. B., Lambert, A., Livesey, N. J., Read, W. G., Waters, J. W., Browell, E. V., Hair, J. W., Avery, M. A., McGee, T. J., Twigg, L. W., Sumnicht, G. K., Jucks, K. W., Margitan, J. J., Sen, B., Stachnik, R. A., Toon, G. C., Bernath, P. F., Boone, C. D., Walker, K. A., Filipiak, M. J., Harwood, R. S., Fuller, R. A., Manney, G. L., Schwartz, M. J., 5 Daffer, W. H., Drouin, B. J., Cofield, R. E., Cuddy, D. T., Jarnot, R. F., Knosp, B. W., Perun, V. S., Snyder, W. V., Stek, P. C., Thurstans, R. P., and Wagner, P. A.: Validation of Aura Microwave Limb Sounder stratospheric ozone measurements, J. Geophys. Res., 113, D15S20, doi:10.1029/2007JD008771, 2008. 29360, 29363

Geer, A. J., Lahoz, W. A., Bekki, S., Bormann, N., Errera, Q., Eskes, H. J., Fonteyn, D., Jackson, D. R., Juckes, M. N., Massart, S., Peuch, V.-H., Rharmili, S., and Segers, A.: The ASSET intercomparison of ozone analyses: method and first results, Atmos. Chem. Phys., 6, 5445-5474, doi:10.5194/acp-6-5445-2006, 2006. 29366, 29367

Huijnen, V., Williams, J., van Weele, M., van Noije, T., Krol, M., Dentener, F., Segers, A., Houweling, S., Peters, W., de Laat, J., Boersma, F., Bergamaschi, P., van Velthoven, P., Le Sager, P., Eskes, H., Alkemade, F., Scheele, R., Nédélec, P., and Pätz, H.-W.: The global chemistry transport model TM5: description and evaluation of the tropospheric chemistry version 3.0, Geosci. Model Dev., 3, 445-473, doi:10.5194/gmd-3-445-2010, 2010. 29359

Lahoz, W. A., Errera, Q., Swinbank, R., and Fonteyn, D.: Data assimilation of stratospheric constituents: a review, Atmos. Chem. Phys., 7, 5745-5773, doi:10.5194/acp-7-5745-2007, 2007. 29359

Lahoz, W. A., Errera, Q., Viscardy, S., and Manney, G. L.: The 2009 stratospheric major warming described from synergistic use of BASCOE water vapour analyses and MLS observations, Atmos. Chem. Phys., 11, 4689-4703, doi:10.5194/acp-11-4689-2011, 2011. 29359

Levelt, P. F., van den Oord, G. H. J., Dobber, M. R., Malkki, A., Visser, H., de Vries, J., Stammes, P., Lundell, J. O. V., and Saari, H.: The ozone monitoring instrument, IEEE T. Geosci. Remote Sens., 44, 1093-1101, 2006. 29360, 29365

Liu, Z.-Q. and Rabier, F.: The potential of high-density observation for numerical weather prediction: A study with simulated observations, Q. J. Roy. Meteor. Soc., 129, 3013-3035, 2003. 29381

30 Livesey, N. J., Filipiak, M. J., Froidevaux, L., Read, W. G., Lambert, A., Santee, M. L., Jiang, J. H., Pumphrey, H. C., Waters, J. W., Cofield, R. E., Cuddy, D. T., Daffer, W. H., Drouin, B. J., Fuller, R. A., Jarnot, R. F., Jiang, Y. B., Knosp, B. W., Li, Q. B., Perun, V. S., Schwartz, M. J., Snyder, W. V., Stek, P. C., Thurstans, R. P., Wagner, P. A., Avery, M., Brow-

High resolution assimilation

B. Pajot et al.

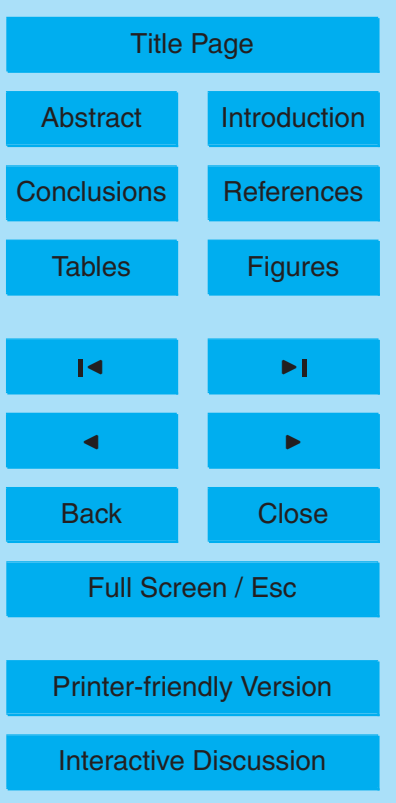

Interactive Discussion 
ell, E. V., Cammas, J.-P., Christensen, L. E., Diskin, G. S., Gao, R.-S., Jost, H.-J., Loewenstein, M., Lopez, J. D., Nédélec, P., Osterman, G. B., Sachse, G. W., and Webster, C. R.: Validation of aura microwave limb sounder $\mathrm{O}_{3}$ and $\mathrm{CO}$ observations in the upper troposphere and lower stratosphere, J. Geophys. Res., 113, D15S02, doi:10.1029/2007JD008805, 2008. 5 29360, 29363

Logan, J. A.: An analysis of ozonesonde data for the troposphere: Recommendations for testing 3-D models and development of a gridded climatology for tropospheric ozone, J. Geophys. Res., 104, 115-149, 1999. 29366

Lorenc, A. C.: A global three-dimensional multivariate statistical interpolation scheme, Mon.

Weather Rev., 109, 701-721, 1981. 29360

Massart, S., Clerbaux, C., Cariolle, D., Piacentini, A., Turquety, S., and Hadji-Lazaro, J.: First steps towards the assimilation of IASI ozone data into the MOCAGE-PALM system, Atmos. Chem. Phys., 9, 5073-5091, doi:10.5194/acp-9-5073-2009, 2009. 29362, 29368, 29370

Massart, S., Piacentini, A., and Pannekoucke O.: Importance of using an ensemble estimated 15 background error covariances for the quality of atmospheric ozone analyses, Q. J. Roy. Meteor. Soc., accepted, 2011. 29364, 29368, 29369, 29371

Pannekoucke, O. and Massart, S.: Estimation of the local diffusion tensor and normalization for heterogeneous correlation modelling using a diffusion equation, Q. J. Roy. Meteor. Soc., 134, 1425-1438, doi:10.1002/qj.288, 2008. 29370

Peuch, V.-H.: MOCAGE, MOdèle de Chimie Atmosphérique à Grande Échelle, Acte des Ateliers de Modélisation de l'Atmosphère, 42, avenue Gaspard Coriolis, 31100 Toulouse, 33-36, 1999. 29367

Rotman, D. A., Tannahill J. R., Kinnison D. E., Connell, P. S., Bergmann, D., Proctor, D., Rodriguez, J. M., Lin, S. J., Rood, R. B., Prather, M. J., Rasch, P. J., Considine, D. B., Ramaroson, R., and Kawa, S. R.: Global modeling initiative assessment model: model description, integration, and testing of the transport shell, J. Geophys. Res., 106, 1669-1691, 2010. 29359

Scannell, C., Hurtmans, D., Boynard, A., Hadji-Lazaro, J., George, M., Delcloo, A., Tuinder, O., Coheur, P.-F., and Clerbaux, C.: A review of the ozone hole from 2008 to 2010 as observed by IASI, Atmos. Meas. Tech. Discuss., 4, 4717-4752, doi:10.5194/amtd-4-4717-2011, 2011. 29362

Smit, H. and Kley, D.: JOSIE: The 1996 WMO International intercomparison of ozonesondes under quasi flight conditions in the environmental simulation chamber at Jülich,

\section{ACPD}

11, 29357-29406, 2011

\section{High resolution assimilation}

B. Pajot et al.

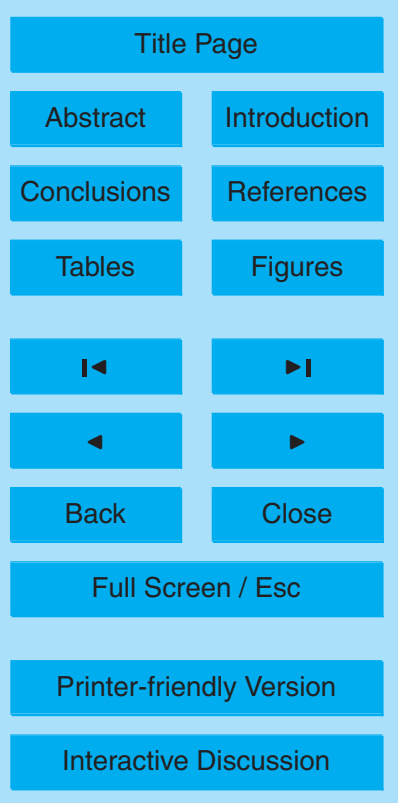


WMO/IGACReport, WMO Global Atmosphere Watch report series, No. 130 (Technical Document No. 926), World Meteorological Organization, Geneva, 1998. 29366

van $\operatorname{der}$ A, R. J., Allaart, M. A. F., and Eskes, H. J.: Multi sensor reanalysis of total ozone, Atmos. Chem. Phys., 10, 11277-11294, doi:10.5194/acp-10-11277-2010, 2010. 29359

5 Veefkind, J. P., de Haan, J. F., Brinksma, E. J., Kroon, M., and Levelt, P. F.: Total ozone from the Ozone Monitoring Instrument (OMI) using the DOAS technique, geoscience and remote sensing, IEEE T. Geosci. Remote, 44, 1239-1244, doi:10.1109/TGRS.2006.871204, 2006. 29365

Weaver, A. and Courtier, P.: Correlation modelling on the sphere using a generalized diffusion equation, Q. J. Roy. Meteor. Soc., 127, 1815-1846, 2001. 29369

\section{ACPD}

11, 29357-29406, 2011

\section{High resolution assimilation}

B. Pajot et al.

Title Page

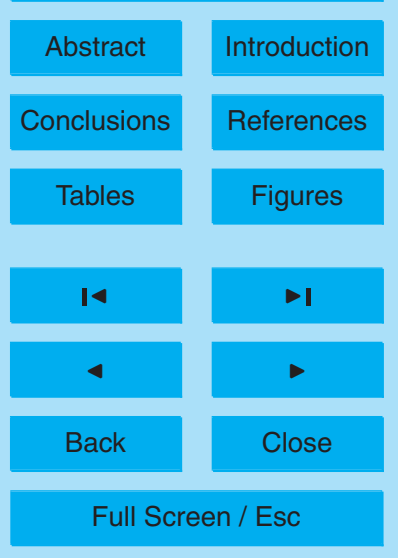

Printer-friendly Version

Interactive Discussion 


\section{ACPD}

11, 29357-29406, 2011

\section{High resolution assimilation}

B. Pajot et al.

Table 1. Number of super-observations from IASI and OMI total ozone columns, depending on the grid used for the averaging, and number of MLS ozone profiles, produced per day and per band of latitude (averaged for the month of September and rounded to the nearest decade).

\begin{tabular}{lrlrlc}
\hline Lat. bands & \multicolumn{2}{c}{ IASI } & \multicolumn{2}{c}{ OMI } & MLS \\
& T42 & T170 & \multicolumn{2}{c}{ T42 T170 } & \\
\hline $90^{\circ} \mathrm{S}: 60^{\circ} \mathrm{S}$ & 7760 & 33510 & 4540 & 27990 & 420 \\
$60^{\circ} \mathrm{S}: 30^{\circ} \mathrm{S}$ & 4100 & 21840 & 3510 & 25300 & 300 \\
$30^{\circ} \mathrm{S}: 30^{\circ} \mathrm{N}$ & 6190 & 41600 & 4930 & 38000 & 530 \\
$30^{\circ} \mathrm{N}: 60^{\circ} \mathrm{N}$ & 4140 & 22880 & 3420 & 25530 & 320 \\
$60^{\circ} \mathrm{N}: 90^{\circ} \mathrm{N}$ & 7620 & 30700 & 8150 & 61980 & 450 \\
Global & 28370 & 148420 & 24250 & 176290 & 2020 \\
\hline
\end{tabular}

Title Page

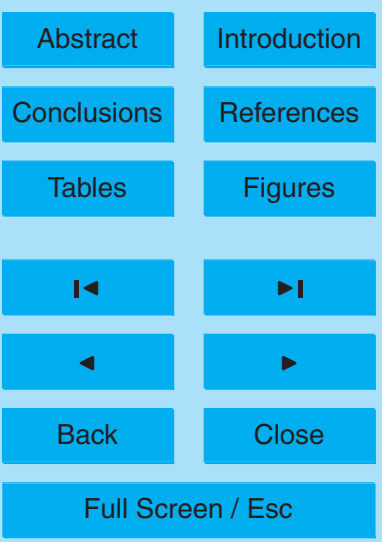

Printer-friendly Version

Interactive Discussion 


\section{ACPD}

11, 29357-29406, 2011

\section{High resolution assimilation \\ B. Pajot et al.}

Table 2. Description of experiments.

\begin{tabular}{lccc}
\hline $\begin{array}{l}\text { Exp. } \\
\text { name }\end{array}$ & $\begin{array}{c}\text { Model } \\
\text { hor. res. }\end{array}$ & $\begin{array}{c}\text { Assim. } \\
\text { dataset }\end{array}$ & $\begin{array}{c}\text { Correlation hor. } \\
\text { len.-scale }\end{array}$ \\
\hline Ml & T42 & no & no \\
Mh & T170 & no & no \\
All & T42 & T42 IASI \& MLS & $2.5^{\circ}$ \\
Ahl & T170 & T42 IASI \& MLS & $2.5^{\circ}$ \\
Ahh & T170 & T170 IASI \& MLS & $0.7^{\circ}$ \\
\hline
\end{tabular}

Title Page

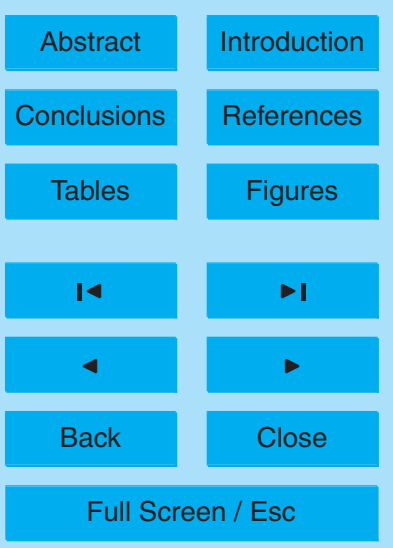

Printer-friendly Version

Interactive Discussion 


\section{ACPD}

11, 29357-29406, 2011

\section{High resolution assimilation \\ B. Pajot et al.}

Table 3. IASI super-observations features. See text for details.

\begin{tabular}{|c|c|c|c|}
\hline Latitudes & $\begin{array}{c}\text { Grid T42 } \\
\text { Nb. of obs. }\end{array}$ & Std. & $\begin{array}{l}\text { Grid T170 } \\
\text { Nb. of obs. }\end{array}$ \\
\hline $90^{\circ} \mathrm{S}: 60^{\circ} \mathrm{S}$ & 5.2 & 4.3 & 1.2 \\
\hline $60^{\circ} \mathrm{S}: 30^{\circ} \mathrm{S}$ & 10.1 & 2.4 & 1.7 \\
\hline $30^{\circ} \mathrm{S}: 30^{\circ} \mathrm{N}$ & 14.8 & 2 & 2.2 \\
\hline $30^{\circ} \mathrm{N}: 60^{\circ} \mathrm{N}$ & 10.8 & 2.3 & 1.8 \\
\hline $60^{\circ} \mathrm{N}: 90^{\circ} \mathrm{N}$ & 5 & 2.3 & 1.2 \\
\hline Global & 10.2 & 2.5 & 1.7 \\
\hline
\end{tabular}

Title Page

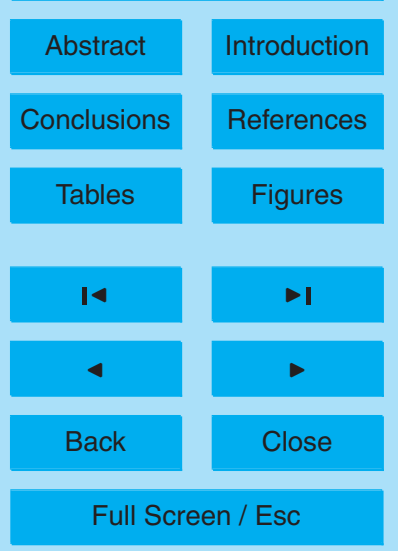

Printer-friendly Version

Interactive Discussion 


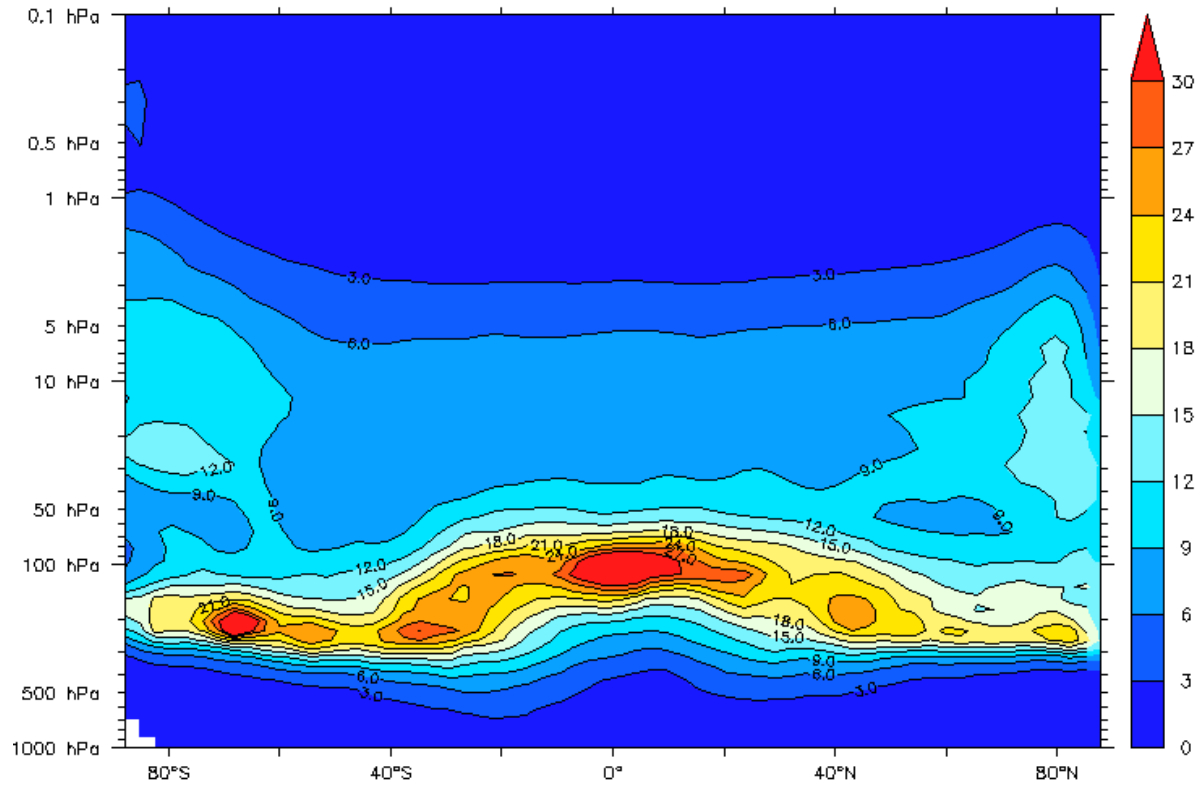

Fig. 1. Zonal mean of the effective ozone standard deviation averaged for the month of September in \% on the T42 grid. See text for details.

\section{ACPD}

11, 29357-29406, 2011

High resolution assimilation
B. Pajot et al.

Title Page

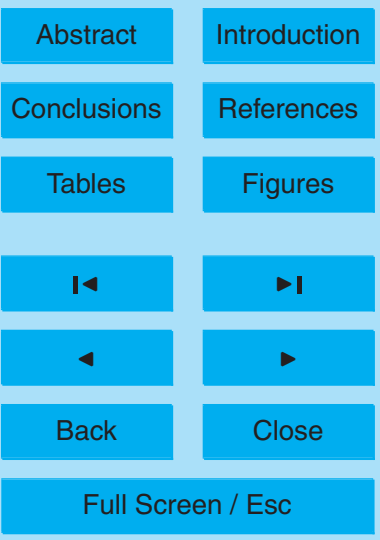

Printer-friendly Version

Interactive Discussion 


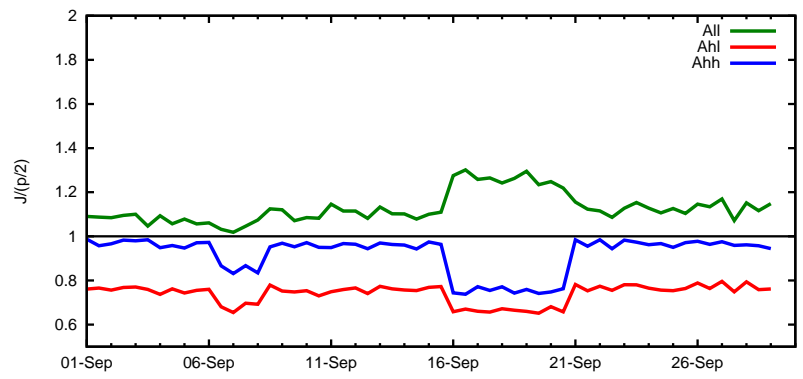

\section{ACPD}

11, 29357-29406, 2011

\section{High resolution assimilation}
B. Pajot et al.
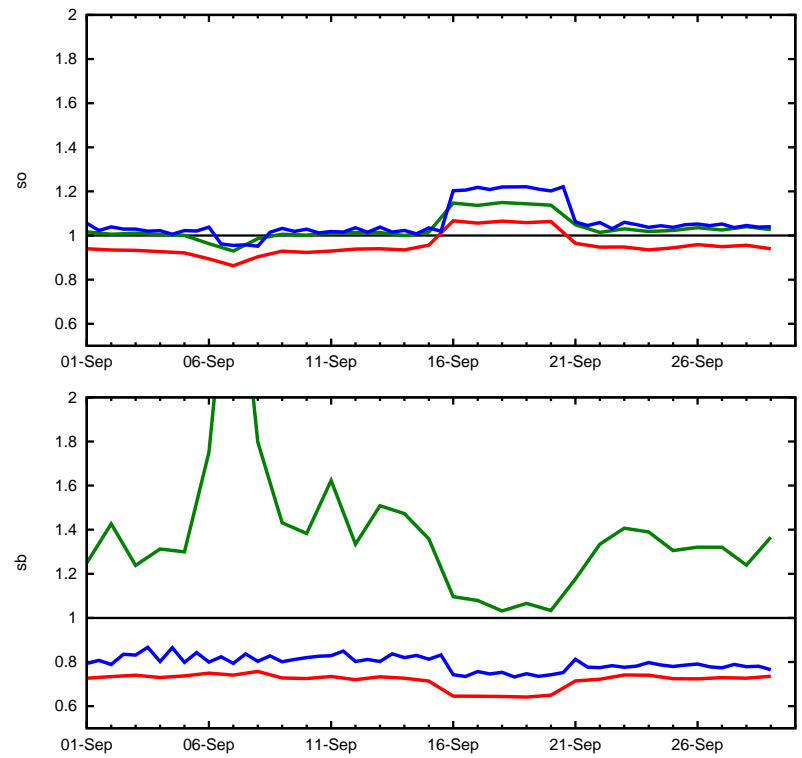

Fig. 2. Diagnostics on data assimilations for All (green), Ahl (red) and Ahh (blue). On top panel values of the cost function at the minimum divided by half the number of observations. On the middle and lower panels values of the multiplicative correction coefficients for the observation and the forecast errors, respectively.

\section{5}




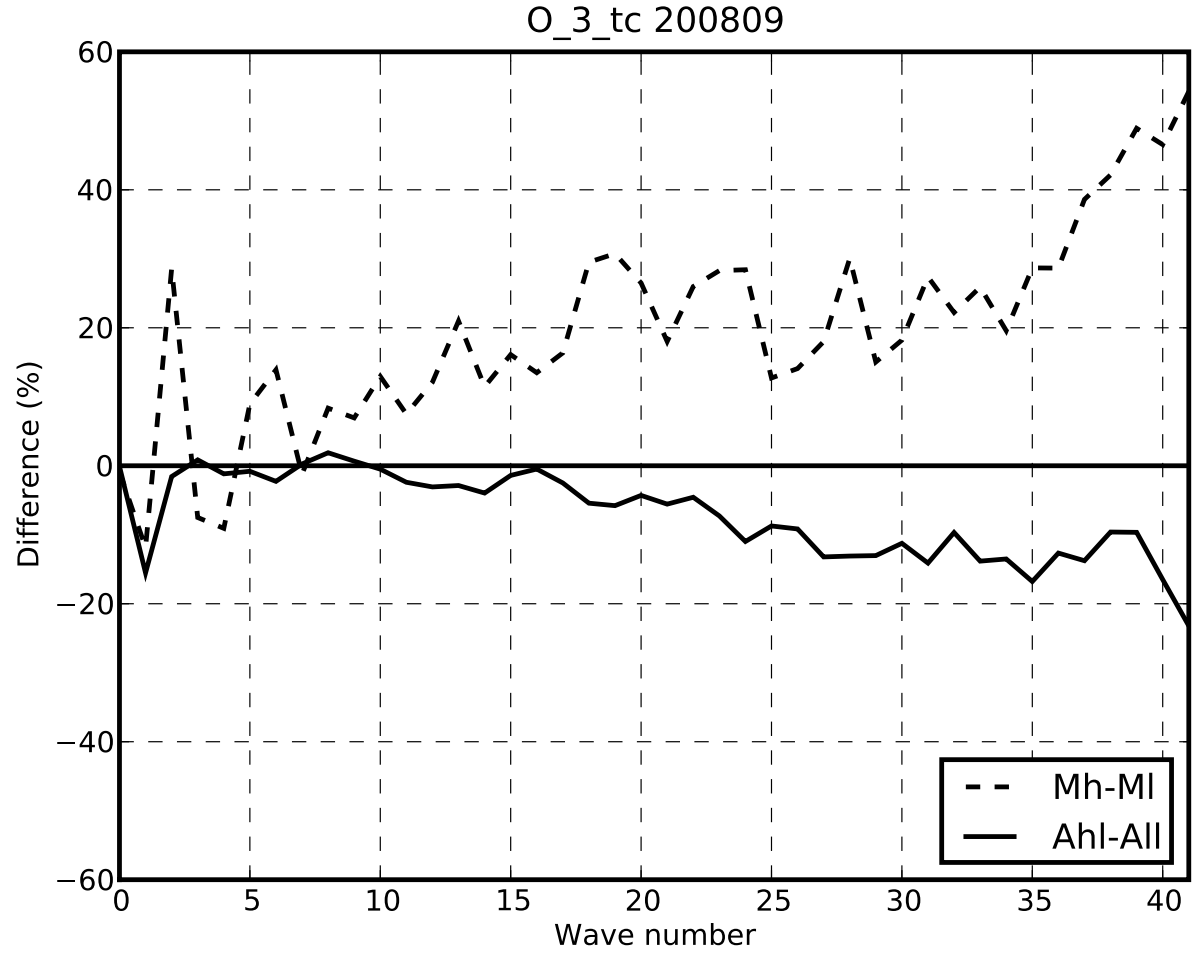

Fig. 3. Monthly average (in \%) of the daily differences between the energy spectra $\boldsymbol{e}_{\mathrm{h}}$ and $\boldsymbol{e}_{\mathrm{I}}$ (dashed line), normalized by $\left(\overline{\boldsymbol{e}_{\mathrm{h}}}+\overline{\boldsymbol{e}_{\mid}}\right) / 2$, and between the energy spectra $\boldsymbol{e}_{\mathrm{hl}}$ and $\boldsymbol{e}_{\|}$(solid line), normalized by $\left(\overline{\boldsymbol{e}_{\mathrm{hl}}}+\overline{\boldsymbol{e}_{\|}}\right) / 2$. See text for details.

\section{ACPD}

$11,29357-29406,2011$

\section{High resolution assimilation}
B. Pajot et al.

Title Page

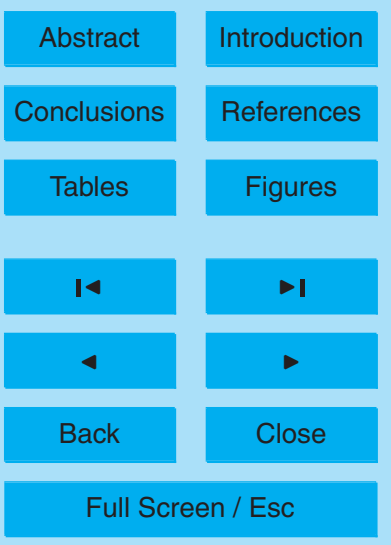

Printer-friendly Version

Interactive Discussion

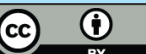




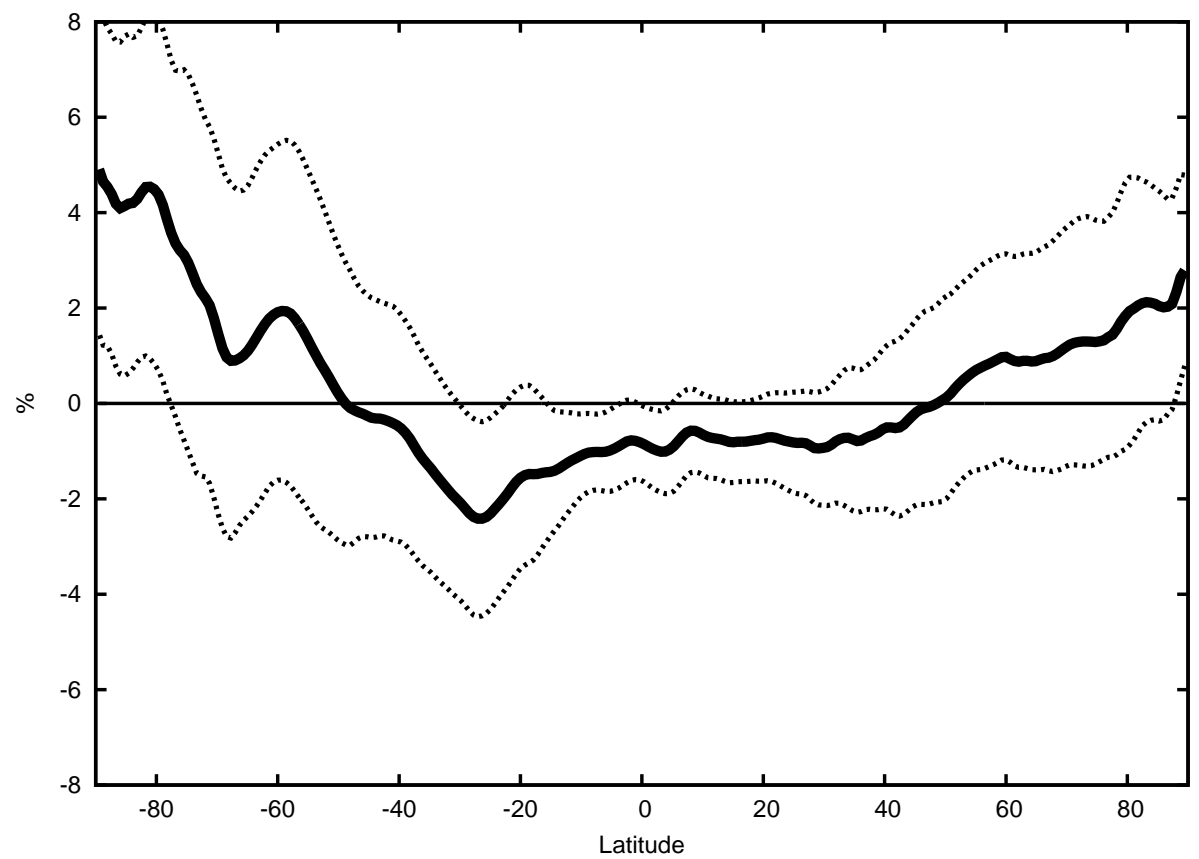

Fig. 4. Zonal difference between the total ozone columns (in \%) computed from the Mh and Ml experiments, normalized by the total ozone columns from the ERA-Interim reanalysis. The upper and lower dashed lines represent the difference plus or minus the zonal average of the standard deviations. A positive value of the difference means that the total ozone columns from the Mh experiment are higher than the ones from the Ml experiment.

\section{ACPD}

11, 29357-29406, 2011

\section{High resolution assimilation}
B. Pajot et al.

Title Page

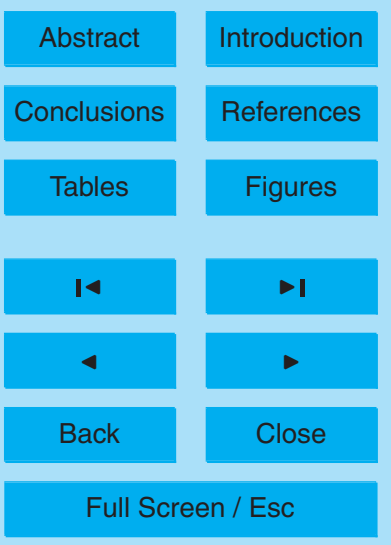

Printer-friendly Version

Interactive Discussion 


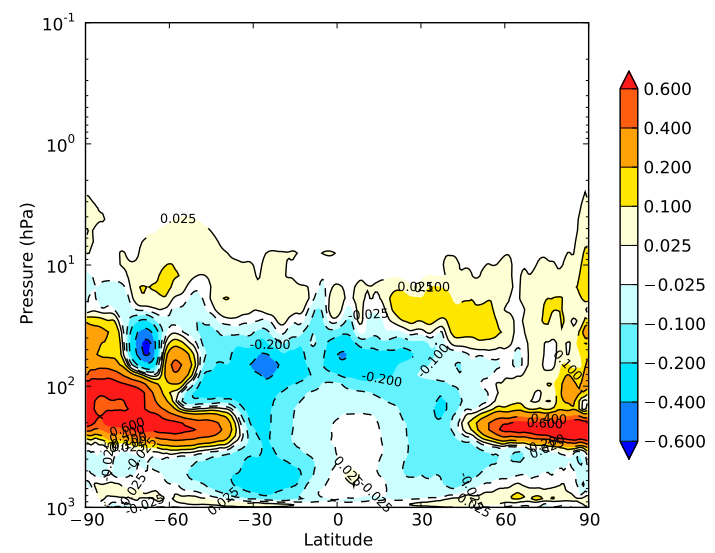

\section{ACPD}

11, 29357-29406, 2011

\section{High resolution assimilation \\ B. Pajot et al.}
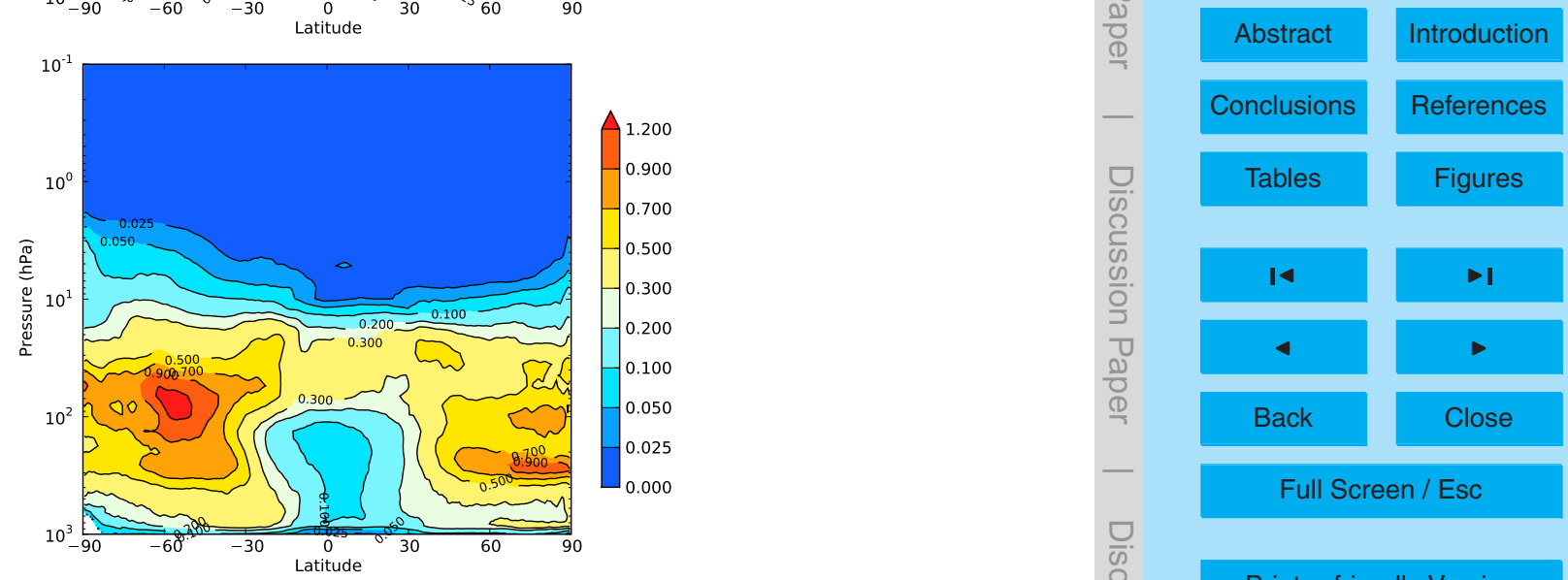

Printer-friendly Version

Fig. 5. Zonal difference (top) and standard deviation (bottom) between the ozone partial pressure from the $\mathrm{Ml}$ and $\mathrm{Mh}$ experiments (in $\mathrm{mPa}$ ). A positive value of the difference means that the ozone concentrations from the Mh experiment are higher than the ones from the $\mathrm{Ml}$ experiment. 

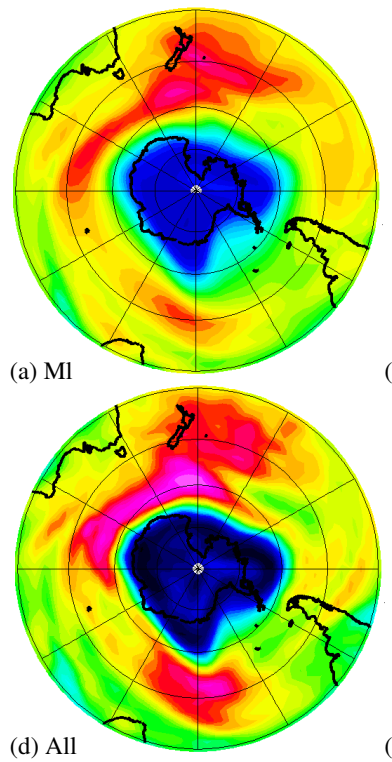

(b) $\mathrm{Mh}$
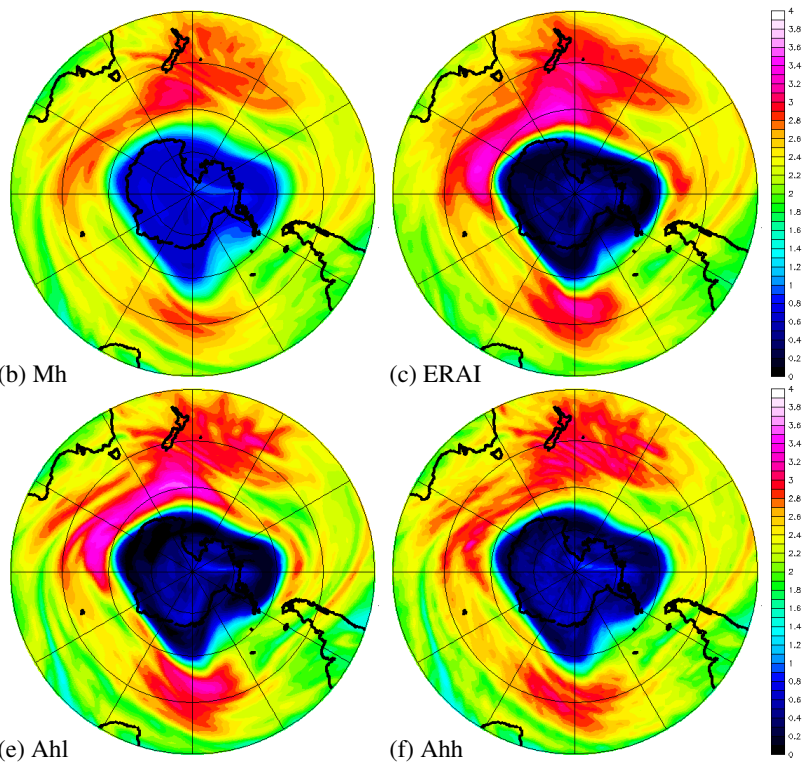

(f) Ahh

\section{ACPD}

11, 29357-29406, 2011

High resolution assimilation

B. Pajot et al.

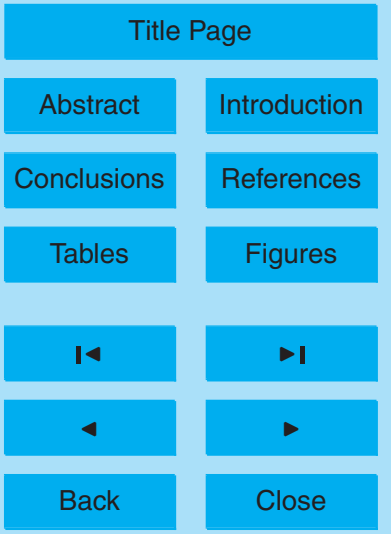

Full Screen / Esc

Printer-friendly Version

Interactive Discussion
Fig. 6. Ozone volume mixing ratio (in Parts per Million by Volume or ppmv) centred over the Southern Hemisphere at $55 \mathrm{hPa}$ on 30 September at 12:00 UTC. Data come from our 5 experiments (a, b, $\mathbf{d}-\mathbf{f}$; see Table 2 for details) and from the ERAI reanalysis (c). 

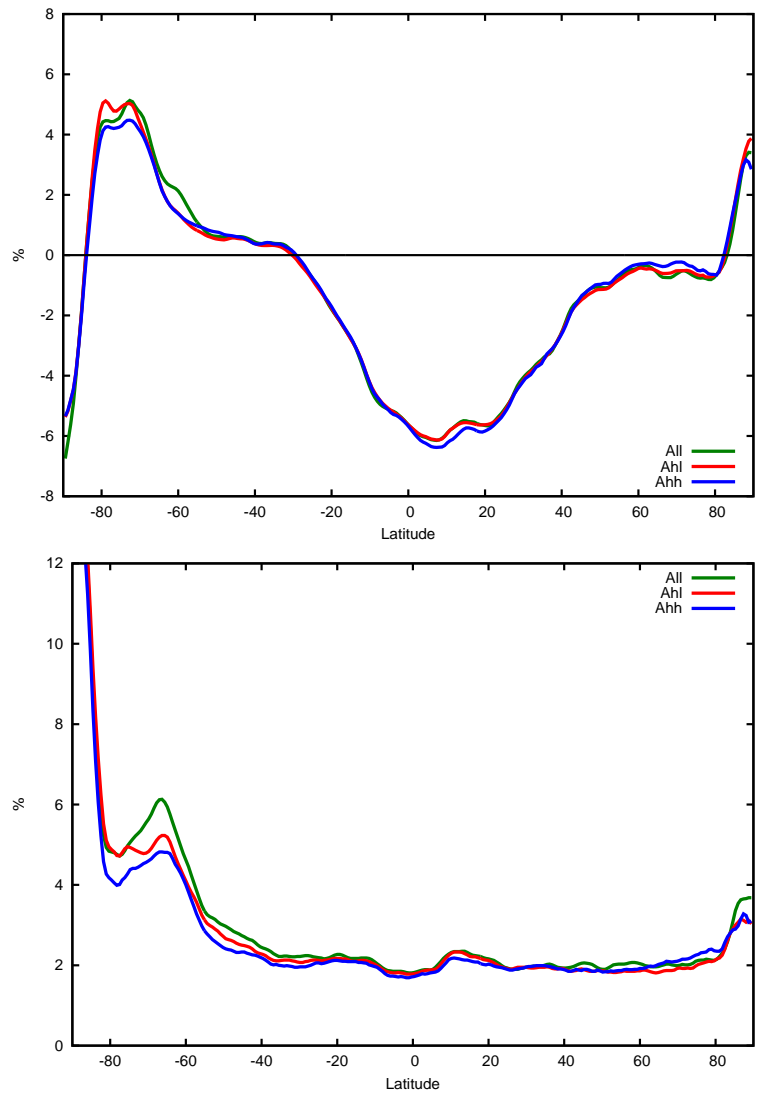

\section{ACPD}

11, 29357-29406, 2011

\section{High resolution assimilation}
B. Pajot et al.

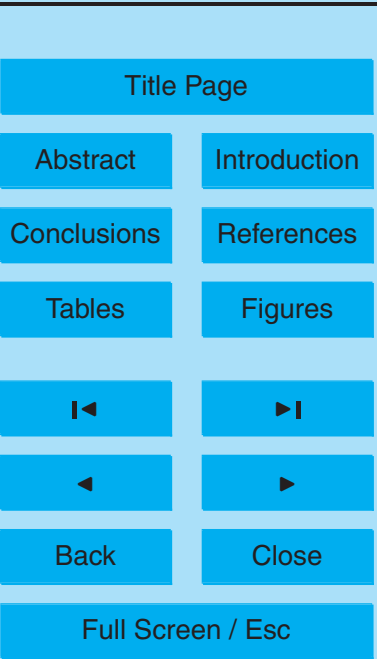

Printer-friendly Version

Fig. 7. Total ozone columns zonal difference (top, in \%) and zonal average of the total ozone columns standard deviation (bottom, in \%) between (All - ERA-interim) (green), (Ahl - ERAInterim) (red) and (Ahh - ERA-interim) (blue). See text for details. The differences are normalized by the total ozone columns from the ERA-Interim reanalysis.

Interactive Discussion 


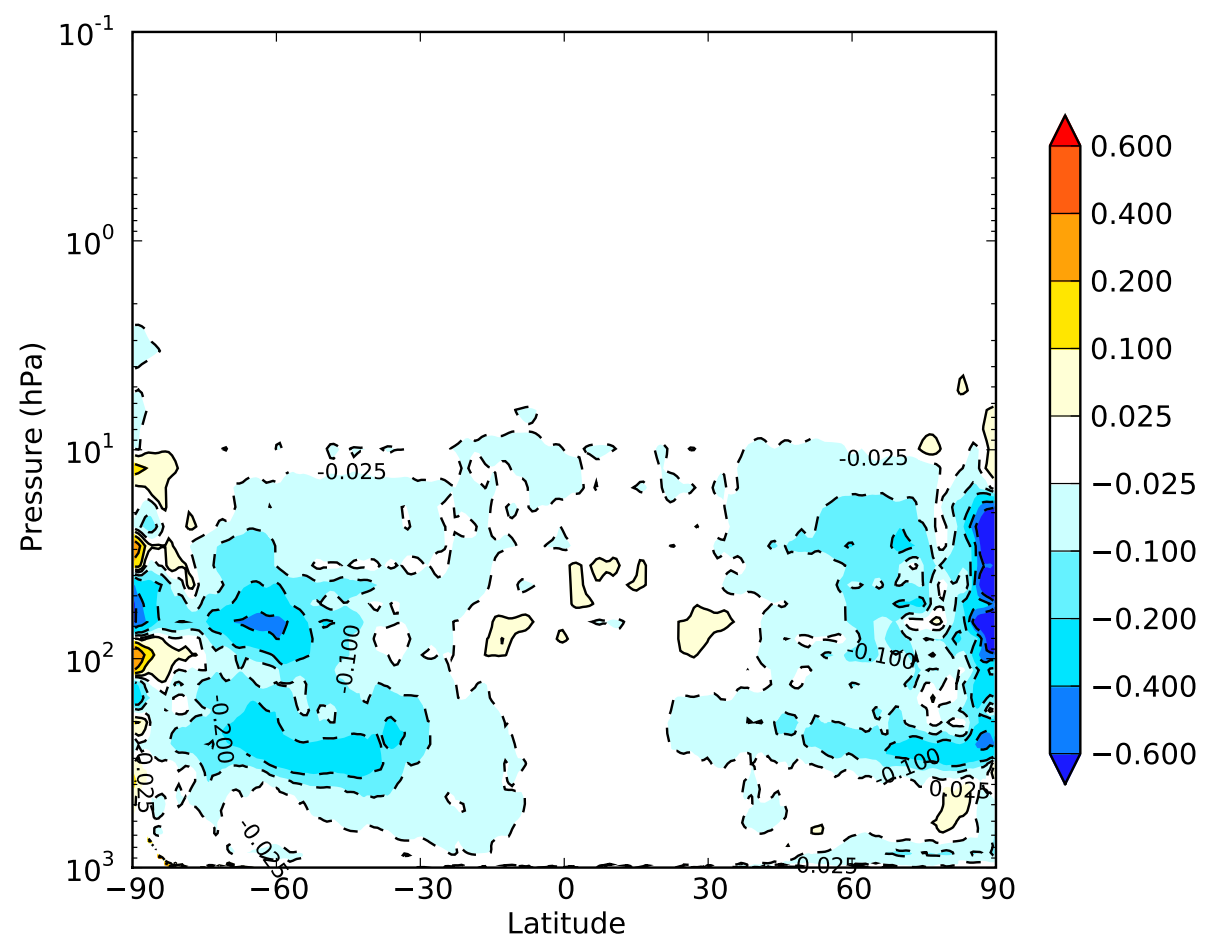

\section{ACPD}

11, 29357-29406, 2011

\section{High resolution assimilation}

B. Pajot et al.

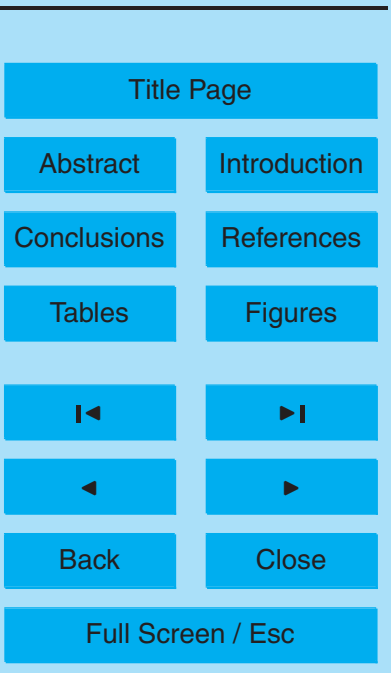

Printer-friendly Version

Ahl analysis and the ERA-Interim reanalysis minus the standard deviation of the differences between the All analysis and the ERA-Interim reanalysis (in $\mathrm{mPa}$ ). Positive values indicate that the All experiment has a better agreement with the ERA-Interim reanalysis than the Ahl experiment, and negative values the opposite.

Interactive Discussion 

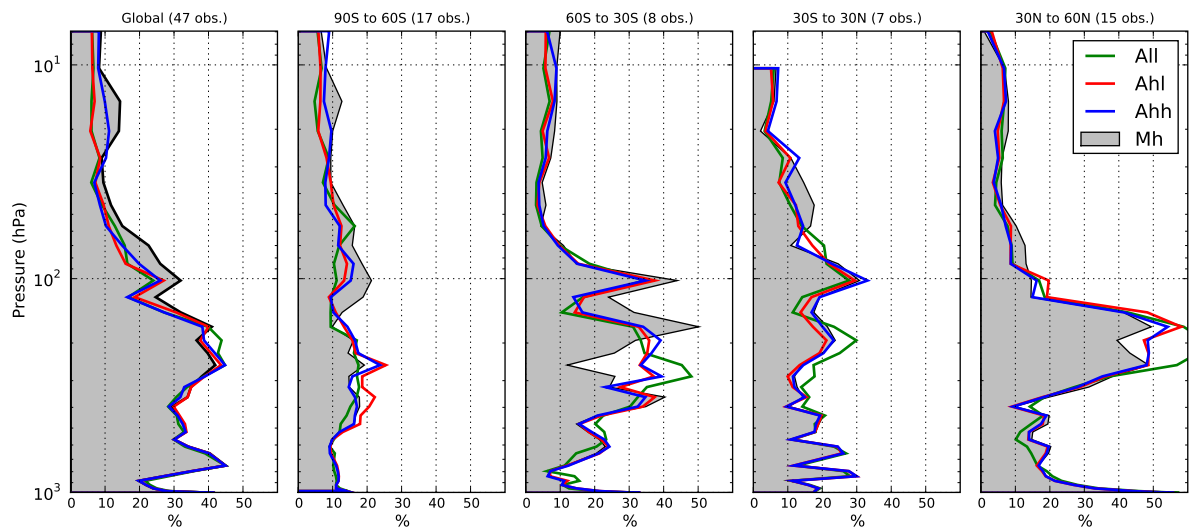

Fig. 9. Zonal average of the standard deviations of (Mh - ozonesondes) (gray-colored), (All ozonesondes) (green), (Ahl - ozonesondes) (red) and (Ahh - ozonesondes) (blue), normalized by the climatology. The latitude band limits and the number of used ozonesonde profiles are given in the title of each sub-plot. See text for details.

\section{ACPD}

11, 29357-29406, 2011

\section{High resolution assimilation}
B. Pajot et al.

\section{Title Page}

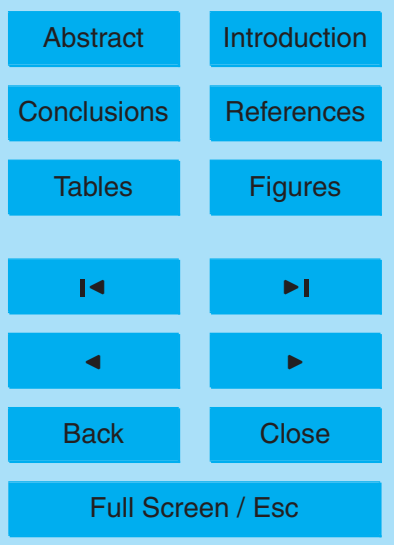

Printer-friendly Version

Interactive Discussion 


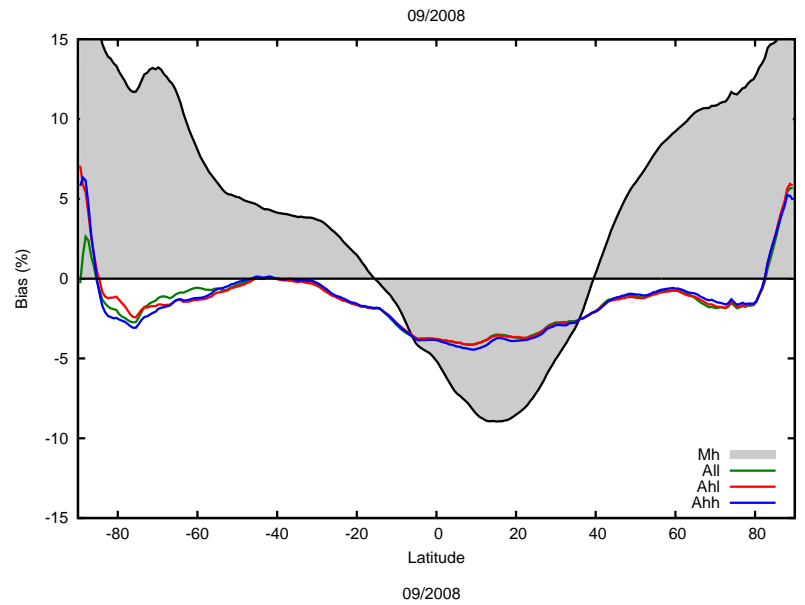

\section{ACPD}

11, 29357-29406, 2011

\section{High resolution assimilation}
B. Pajot et al.

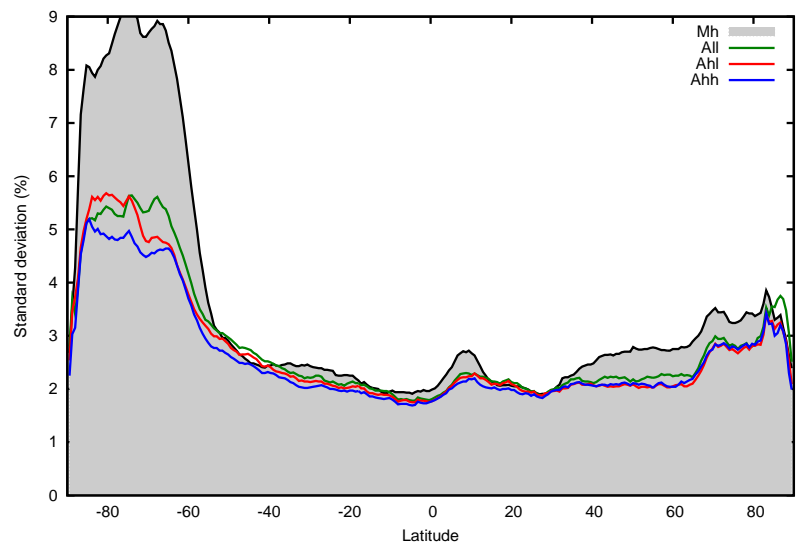

\section{Abstract}

Title Page

Introduction

Conclusions

References

Tables

Figures

\section{4}

4

Back

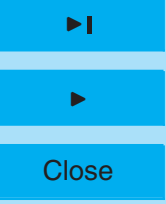

Full Screen / Esc

Printer-friendly Version

Interactive Discussion

Fig. 10. Zonal difference (top, in \%) and zonal average of the standard deviation (bottom, in \%) between the total ozone columns computed from the Mh simulation and OMI (gray-colored), from the All analysis and OMI (green), from the Ahl analysis and OMI (red) and from the Ahh analysis and OMI (blue). See text for details. 


\section{ACPD}

11, 29357-29406, 2011
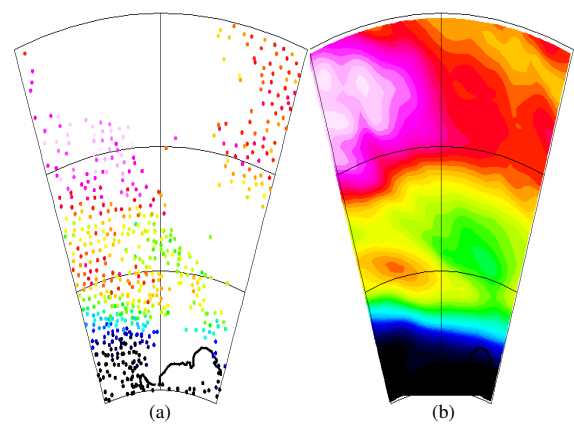

(b)
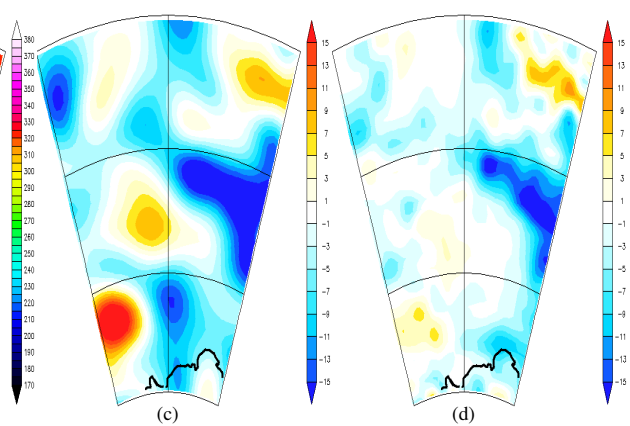

Fig. 11. Zoom over the SP between the latitudes 70 and $40^{\circ} \mathrm{S}$ and between the longitudes 20 and $60^{\circ} \mathrm{E}$ on 30 September. On panel (a), the T170 IASI measurements cumulated between 00:00 and 12:00 UTC. On panel (b), the total ozone columns field at 00:00 UTC resulting from the Ahh experiment after a $12 \mathrm{~h}$ forecast. Data values on panels (a) and (b) are in Dobson Units (DU) as specified in the (b) legend. On panels (c) and (d) is shown the increment (in DU) computed at 00:00 UTC for the ozone total columns field on (b). The horizontal length-scales of the assimilation are set to $275 \mathrm{~km}$ for (c) and to $77 \mathrm{~km}$ for (d).

\section{High resolution assimilation \\ B. Pajot et al.}

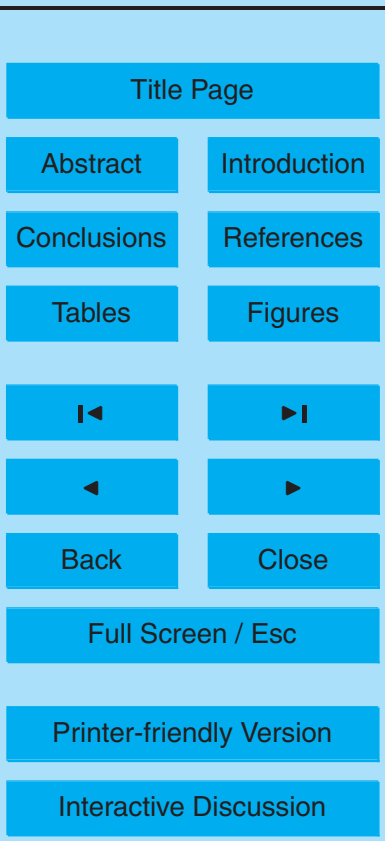


Longitude $60 \mathrm{~W}$
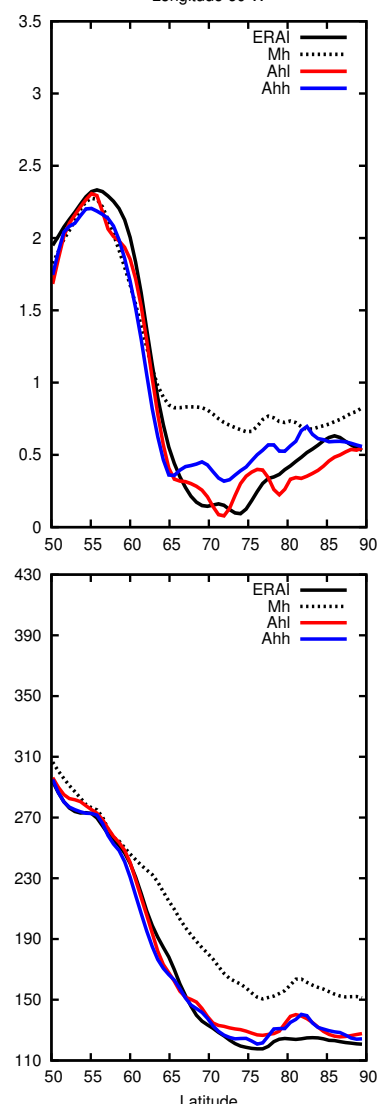

Longitude $120 \mathrm{E}$
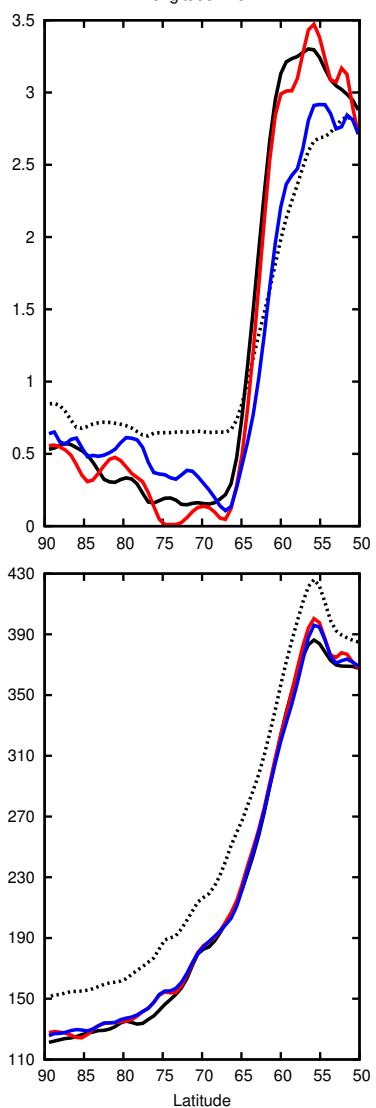

\section{ACPD}

11, 29357-29406, 2011

\section{High resolution assimilation}

B. Pajot et al.

Title Page

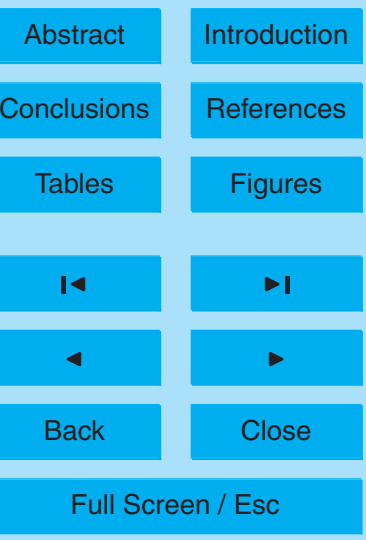

Printer-friendly Version

Interactive Discussion

Fig. 12. Ozone volume mixing ratio (top, in ppmv) and total ozone columns (in DU) along the longitudes $60^{\circ} \mathrm{W}$ on the left and $120^{\circ} \mathrm{E}$ on the right, from latitude $50^{\circ} \mathrm{S}$ to the SP, at $55 \mathrm{hPa}$ on 30 September at 12:00 UTC. Data come from ERAI reanalyses (solid black) and Mh (dashed black), Ahl (red) and Ahh (blue) experiments.

29405 


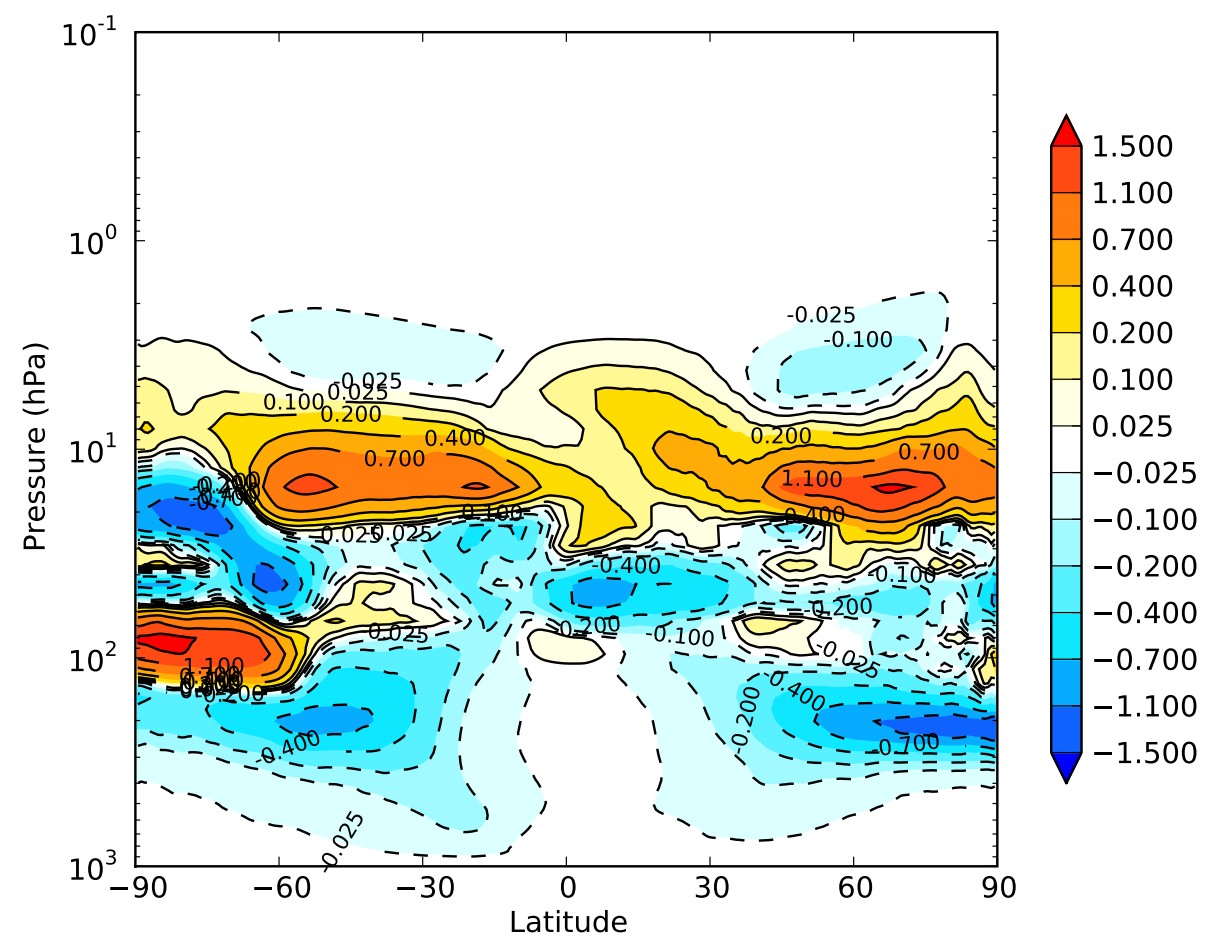

11, 29357-29406, 2011

\section{High resolution assimilation}

B. Pajot et al.

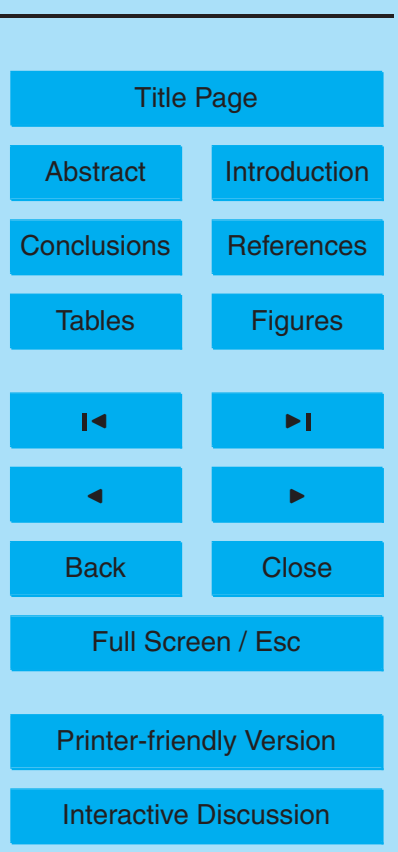

Fig. 13. Zonal difference between the ozone partial pressure from the Ahl and Ahh experiments (in $\mathrm{mPa}$ ). A positive value of the difference means that the ozone concentrations from the Ahh experiment are higher than the ones from the Ahl experiment.

Interactive Discussion 